\title{
Estimation of the Pumping Pressure from Concrete Composition Based on the Identified Tribological Parameters
}

\author{
Chanh-Trung Mai, El-Hadj Kadri, Tien-Tung Ngo, Abdelhak Kaci, and Mustapha Riche \\ Laboratory L2MGC (4114), University of Cergy Pontoise, 9500 Cergy Pontoise, France \\ Correspondence should be addressed to Tien-Tung Ngo; tien-tung.ngo@u-cergy.fr
}

Received 4 June 2014; Revised 6 October 2014; Accepted 6 October 2014; Published 23 November 2014

Academic Editor: Luigi Nicolais

Copyright ( 2014 Chanh-Trung Mai et al. This is an open access article distributed under the Creative Commons Attribution License, which permits unrestricted use, distribution, and reproduction in any medium, provided the original work is properly cited.

\begin{abstract}
A new method is proposed to estimate pumping pressure based on concrete composition without experimental measurements. Previous studies show that the pumping pressure depends on the interface friction between concrete and the wall of the pumping pipes. This friction is determined by the thickness and the rheology of the boundary layer formed at the interface. The latter is mainly formed by water, cement, and fine sand particles which come from concrete. Hence, interface parameters, which are the viscous constant and the interface yield stress, are directly related to concrete composition. In this work, at the first time the interface yield stress model is suggested and validated thanks to an experimental database also carried out in this study with a precision of around $13 \%$. Then, the pressure estimation method is proposed using the two models to calculate the interface parameters. The validation of the method is carried out basing on the comparison with real measurements on the building site. This method enables the calculation of the pumping pressure with a precision of around $15 \%$.
\end{abstract}

\section{Introduction}

Concrete pumping technique is widely used in modern construction field (high rise buildings and long spans bridges...). This technique offers many advantages compared to other traditional ways used in the placement and/or to transport of fresh concrete, including reducing the duration of concrete setting up and allowing transporting concrete continually in difficult to reach locations as discussed elsewhere $[1,2]$. The feasibility that concrete could be pumped is defined as workability, also called pumpability or flowability as discussed by Xie et al. [3]. The main parameters of pumpability have been reviewed and studied [4-8] and can be divided into site conditions (type of pump, size, length and material of pipe, energy use, required flow, etc.) and concrete technology (composition, rheology, age, etc.) as discussed by Jacobsen et al. [9].

Previous studies conclude that for most of concretes, flows occur as a plug in the pumping pipe as discussed elsewhere $[6,10-14]$. In this case, the concrete moves by sliding thanks to a concrete boundary layer formed at the interface. From a theoretical point of view, pumping of concrete would not be possible without the formation of this layer as discussed by Morinaga [11]. When the pumping speed increases and the interface shear stress $(\tau)$ is higher than the concrete yield stress $\left(\tau_{0}\right)$, the concrete zone near the wall starts to be sheared. In this case, the concrete moves by sliding and shearing in the pipe.

Recently, simulations results of Le [6] confirmed clearly that, for ordinary concretes or for high performance concretes (HPC), the concrete moves by sliding thanks to the boundary layer. Moreover, for self-compacting concrete (SCC), shearing component is added to sliding (see Figure 1). In this case, the pumping pressure depends not only on the interface parameters, but also on the rheological parameters.

Knowing the important role of the boundary layer for the pumping pressure and thus the concrete pumpability, many researchers have tried to highlight the relationship between its composition and that of concrete. They have attempted to evaluate the thickness of this layer too. The results of the researches show that the boundary layer consists of water, cement, and fine sand particles which come from concrete as discussed by Ngo et al. [15] and Mechtcherine et al. [1]. Many studies proved that the thickness and rheological properties 


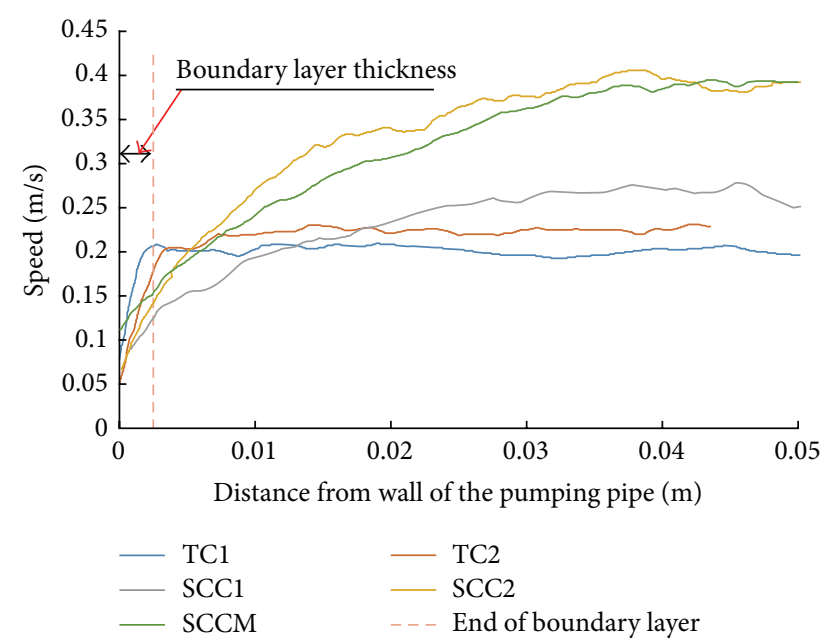

FIGURE 1: Speed profile of different types of concretes as discussed by Le [6].

of the boundary layer seem to depend on the mix proportion of the concrete as discussed elsewhere $[2,16,17]$. From a quantitative point of view, the thickness of this lubrication layer was estimated to be between 1 and $8 \mathrm{~mm}$ as discussed elsewhere $[5,18-20]$.

In order to take into account effect of the flow regime of concrete in the pipe (by sliding or by sliding and shearing) on the pressure, in a previous study of Kaplan [4], a pumping pressure model has been proposed and validated. The model is composed of two tendencies corresponding to each concrete flow regime in the pipe. The first is represented as follows:

$$
P=\frac{2 L}{R}\left(\frac{Q}{3600 \pi R^{2} k_{r}} \eta+\tau_{0 t}\right),
$$

where $\eta$ is viscous constant $(\mathrm{Pa} \cdot \mathrm{s} / \mathrm{m}), Q$ is pumping flow $\left(\mathrm{m}^{3} / \mathrm{h}\right), \tau_{0 t}$ is interface yield stress $(\mathrm{Pa}), R$ is radius of the pumping pipe $(\mathrm{m}), P$ is pumping pressure (bar), $k_{r}$ is filling factor, the value depending on type of pump $\left(k_{r}=0.7\right.$ for automatical pump and $k_{r}=0.8$ for stationary pump), and $L$ is length of the pumping pipe $(\mathrm{m})$.

As discussed below, if the pumping flow is higher than a certain value of pumping flow $\left(Q_{1}\right)$ and it results in an interface shear stress $(\tau)$ that is higher than the concrete yield stress $\left(\tau_{0}\right)$, the concrete zone near the wall starts to be sheared. In this case, the concrete moves by sliding and shearing in the pipe. And calculation of the pumping pressure has to take into account the rheological parameters. The pumping flow $\left(Q_{1}\right)$ beyond that the concrete zone near the wall starts to be sheared can be calculated as follows:

$$
Q_{1}=3600 \frac{\tau_{0}-\tau_{0 t}}{\eta} \pi R^{2} k_{r}
$$

In this case the pumping pressure is calculated by

$$
P=\frac{2 L}{R}\left[\frac{Q / 3600 \pi R^{2} k_{r}-(R / 4 \mu) \tau_{0 t}+(R / 3 \mu) \tau_{0}}{1+R / 4 \mu} \eta+\tau_{0 t}\right],
$$

where $\mu$ is concrete plastic viscosity (Pa.s) and $\tau_{0}$ is concrete yield stress $(\mathrm{Pa})$.

Generally, the mechanical parameters $\left(Q, R, L\right.$, and $\left.k_{r}\right)$ were fixed in the building site. So the pumping pressure depends mainly on the interface parameters (the viscous constant and the interface yield stress) or/and the rheological parameters (the concrete plastic viscosity and the concrete yield stress). The latter is measured by a rheometer. In laboratory, the interface parameters are measured by apparatus called "tribometer." Until now, many types of tribometer were developed as discussed elsewhere [4, 11-14, 18]. All the tribometers have the same goal, that is, to measure the interface friction between the concrete and the pumping pipes wall (generally in steel), according to pumping speed (in the pumping pipe) or rotation speed (in the tribometrical test). The interface friction measurements allow calculating the interface parameters.

Kaplan has also shown in his study, using his tribometer, the relationship between the interface parameters and the interface friction which determines the pumping pressure. That is represented by the following equation:

$$
\tau=\tau_{0 t}+\eta v
$$

where $\tau$ is interface shear stress $(\mathrm{Pa}), \eta$ is viscous constant (Pa.s/m), and $\tau_{0 t}$ is interface yield stress $(\mathrm{Pa})$.

Equation (4) shows an important role of the interface parameters on the pumping pressure. It shows that the viscous constant $(\eta=\partial \tau / \partial \nu)$ determines the evolution of the friction with the pumping speed when the pumping regime is established and that the interface yield stress $\left(\tau_{0 t}\right)$ determines the initial pumping pressure which is necessary to initiate the concrete flow as discussed by Ngo et al. [10].

In this study, the authors are interested in the pumping pressure of ordinary concrete whose rheological behavior can be described as Binghamian fluids as discussed elsewhere [4, $7,8,14,15,19,21-25]$. It is given by

$$
\tau=\tau_{0}+\mu \dot{\gamma}
$$

where $\tau(\mathrm{Pa})$ is the concrete shear stress (called also "interface friction") and $\dot{\gamma}(1 / \mathrm{s})$ is the shearing rate.

Knowing the importance of influence of concrete formulation on the pumping pressure, a method to directly estimate the pressure from ordinary concrete composition without interface parameters measurements thanks to a tribometer has been proposed in this research. This estimation method is proposed basing on models to calculate interface parameters, that is, the viscous constant model and the interface yield stress model. This latter is suggested and validated thanks to an experimental database also carried out in our previous studies with the help of a tribometer developed by Ngo [18].

The used viscous constant $(\eta)$ model is proposed by Ngo et al. $[15,18,25]$. The model is given by

$$
\eta=\frac{10^{\left(3.7\left(\Phi / \Phi^{*}\right)+0.37\right)}}{e_{\text {boundary layer }}}
$$




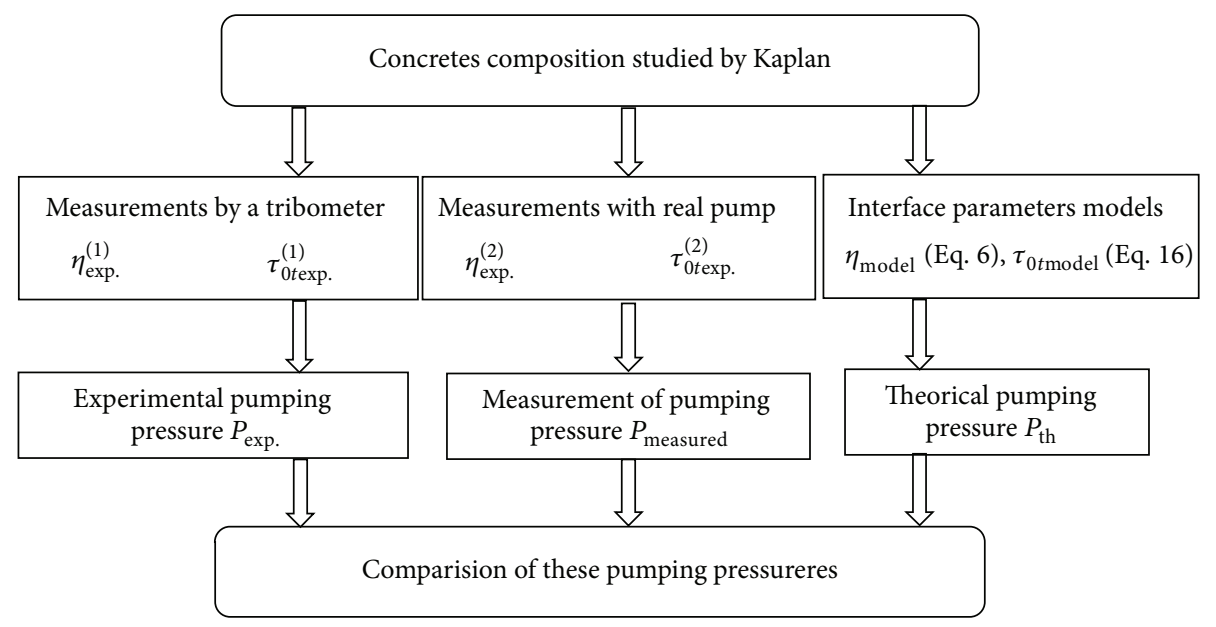

FIGURE 2: Schema of comparison of the pumping pressures.

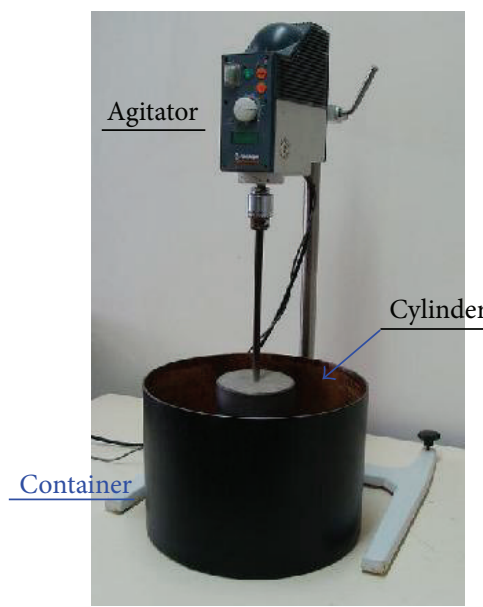

(a)

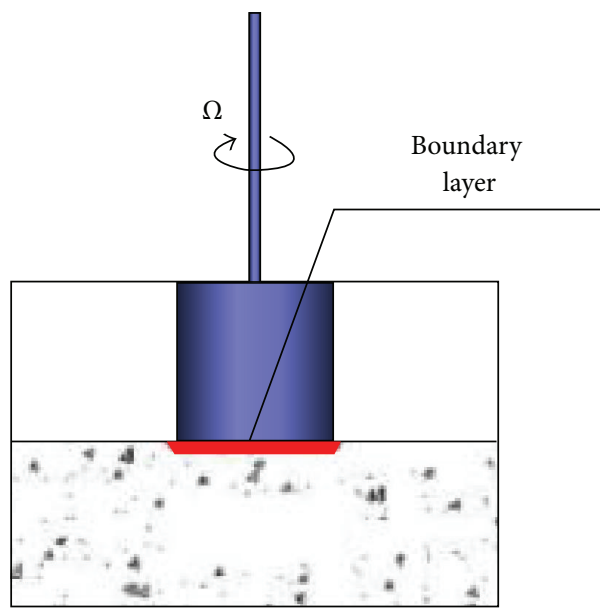

(b)

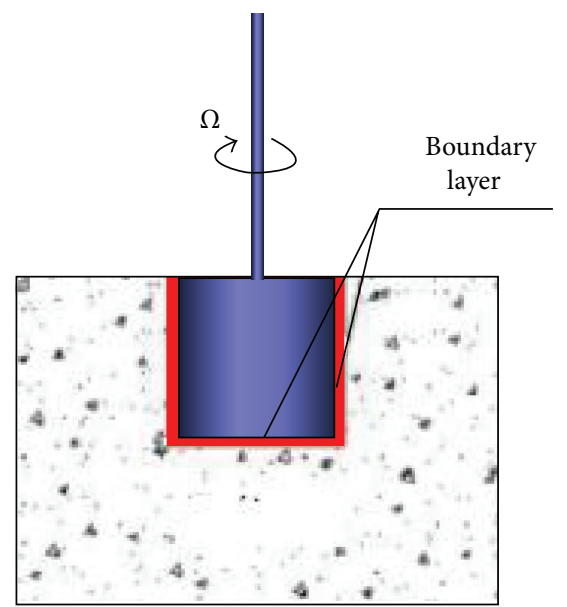

(c)

FiguRE 3: Components of the tribometer and test procedure: (a) tribometer set up; (b) measurement at Step 1; and (c) measurements at Step 2 as proposed by Ngo [18].

where

$$
\begin{gathered}
e_{\text {boundary layer }} \\
= \begin{cases}K \cdot\left(1.18 E_{\max }+4.87\right) & \text { if } 1.3 \mathrm{~mm} \leq E_{\max } \leq 3.5 \mathrm{~mm} \\
9 \mathrm{~mm} & \text { if } E_{\max }>3.5 \mathrm{~mm},\end{cases} \\
K= \begin{cases}1 & \text { if slump } \geq 21 \mathrm{~cm} \\
0.048 \mathrm{Sl} & \text { if slump }<21 \mathrm{~cm}\end{cases}
\end{gathered}
$$

and $E_{\max }(\mathrm{mm})$ is the maximum inter distance between aggregates. This parameter is calculated as proposed by de Larrard and Belloc [21] by

$$
E_{\max }=D\left(\sqrt[3]{\frac{g^{*}}{g}}-1\right) .
$$

$\Phi$ and $\Phi^{*}$ are, respectively, solid concentration and the maximum compactness of granular mixture, $g$ and $g^{*}$ are, respectively, volumetric proportions and the maximum compactness of the granular mixture, and $D$ is maximum diameter of the aggregates $(\mathrm{mm})$.

The estimation pressure method is then validated using many tested concretes compositions in the literature. For each concrete mix proportions chosen, the pumping pressure should be calculated by (1), corresponding to the ordinary concrete, directly from concrete composition using the two interface parameters models ( $\eta$ model and $\tau_{0 t}$ model). Then, this pressure is compared with the pressure calculated by (1) using Kaplan' tribometrical measurements as well as with the real pressure measured with pumps on the building site. The diagram of the comparison is presented in Figure 2.

\section{Building of the Experimental Data Base}

2.1. Tribological Measurements. In this study, a tribometer developed by Ngo [18] is used to achieve the measurements. 


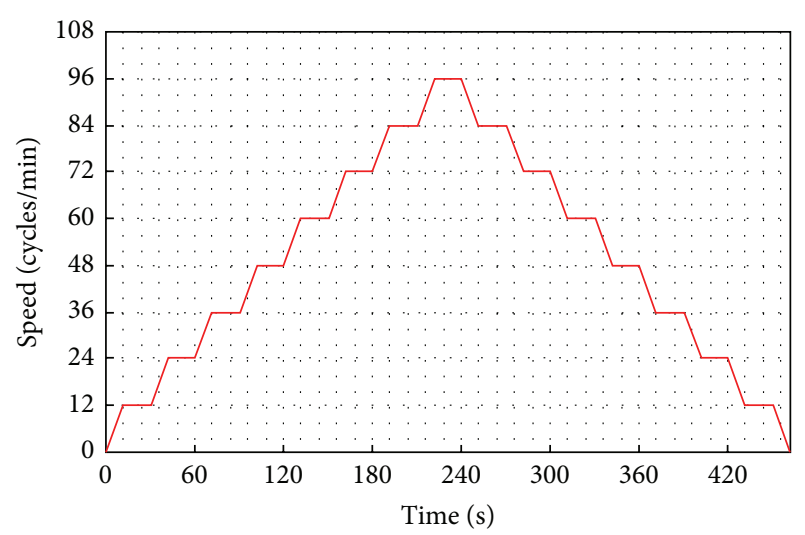

FIGURE 4: Imposed speed profile of the tribometer as proposed by Ngo [18].

The apparatus is composed of three principal parts: an agitator with electronic speed regulation and torque recording; a smooth steel cylinder of $10 \mathrm{~cm}$ height and $10.7 \mathrm{~cm}$ diameter; and a container of $20 \mathrm{~cm}$ height and $30 \mathrm{~cm}$ diameter. The agitator is the main component for carrying out the tests. It is controlled by simple software installed in the computer and placed on top of the rotating cylinder (Figure 3(a)), which is plunged into the concrete container. The tribometer can be used to measure the interface parameters of fresh concrete whose slump is higher than $10 \mathrm{~cm}$.

The tribological test procedure is composed of 5 steps.

Step 1. Fill the first concrete layer up to half of the container and pierce through this layer 25 times as seen in Figure 3(b).

Step 2. Locate the cylinder at the centre of the container and let it stand on the concrete surface by its own weight; the cylinder is then fixed to the agitator axis.

Step 3. Measure the friction torque corresponding to different imposed velocities as seen in Figure 4.

Step 4. Once Step 3 is finished, fill the second layer on top of the first layer to the top of the container and pierce through this layer 25 times as shown in Figure 3(c).

\section{Step 5. Repeat Step 3 and record the new results.}

The interface friction torque is obtained by subtracting results of Step 3 from those from Step 5. For each imposed speed level, the average interface friction on the cylinder circumferential area during the constant rotation speeds is obtained. The obtained interface friction torque was recorded for the decreasing speeds direction to identify the pumping parameters.

Figure 5 presents dynamic response of a tribometer test in the decreasing speeds range, and the corresponding torque to the imposed speed was recorded continuously over time. In order to represent the two different quantities on the same figure, a normalised variable was used.

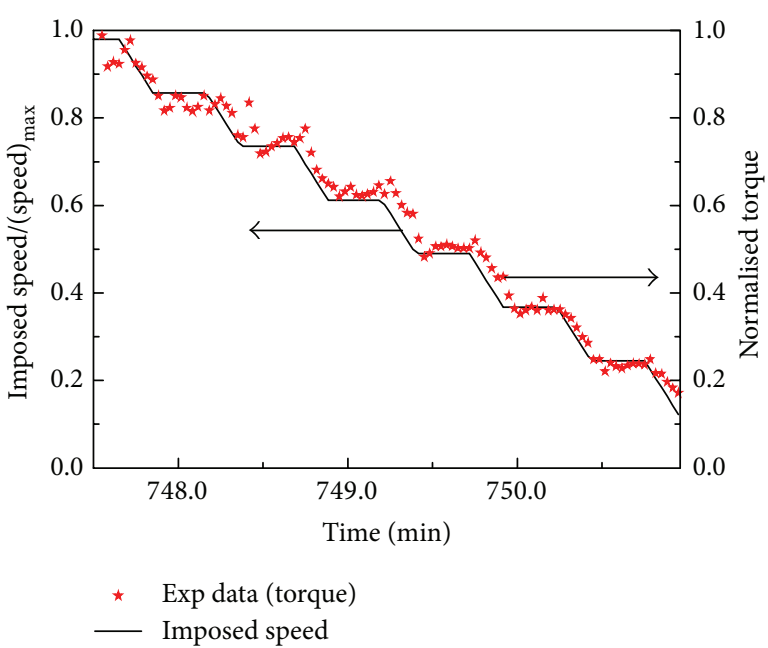

FIGURE 5: Evolution of the imposed speed of the cylinder and of the measured torques according to the time.

It is obvious from the figure that the imposed decreasing speed steps induce the same torque behaviour. The system (soft control, tribometer, and acquisition) responds quite well to the imposed velocities. The tribometer exhibits a good dynamic response and stable steady state torque allowing the identification of average torque for each speed level.

2.2. Measurements Analysis. An example of raw result of the tribometrical test is illustrated in Figure 6(a). The test results can be approximated by an empirical linear function as follows:

$$
T=T_{0}+k \cdot V
$$

where $T(\mathrm{~N} \cdot \mathrm{m})$ is the applied torque to the revolving cylinder; $T_{0}(\mathrm{~N} \cdot \mathrm{m})$ is the initial torque; $k(\mathrm{~N} \cdot \mathrm{m} \cdot \mathrm{s})$ is the linear coefficient; and $V$ (cycles/s) is the cylinder rotating speed.

Using the values of $T_{0}$ and $V$ (fundamental units) obtained from (9) in taking into account the cylinder shape and its dimensions, the interface parameters $\left(\tau_{0 t}\right.$ and $\left.\eta\right)$ can be calculated by

$$
\tau_{0 t}=\frac{T_{0}}{2 \pi R^{2} h}, \quad \eta=\frac{k}{(2 \pi)^{3} R^{3} h} .
$$

Figure 6(b) illustrates evolution of the concrete shear stress with shearing rate and the obtained interface parameters from the raw test result. The illustration shows that the concrete starts to flow only when the concrete shear stress is higher than the interface yield stress. Whenever the concrete flows, the viscous constant determines the evolution of the concrete shear stress with the increase of the shearing rate. Hence, the determination of these interface parameters is particularly important to master the concrete shear stress and thus the pumping pressure in pumping pipe.

2.3. Materials and Mix Proportions. All studied concretes in this work were produced with the cement CEM I 52.5 


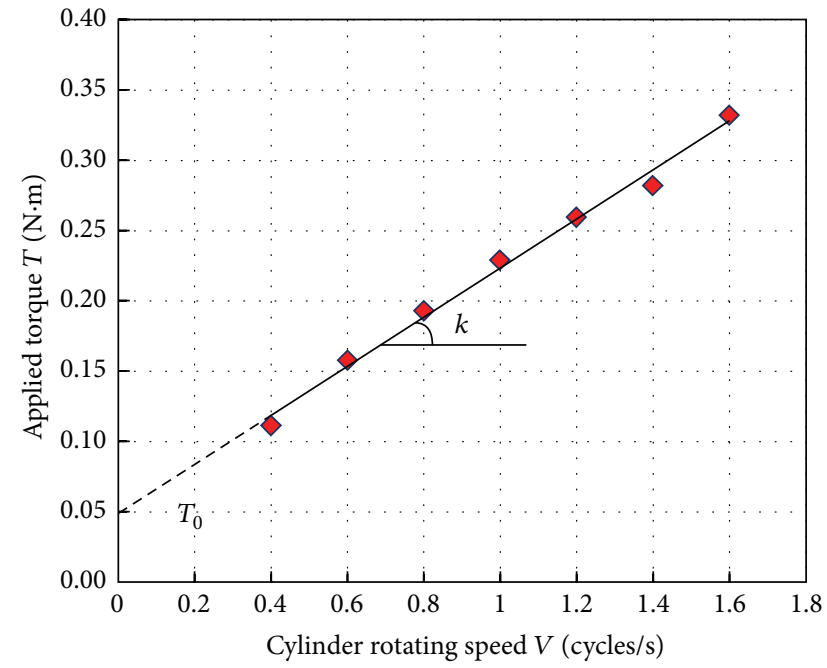

(a)

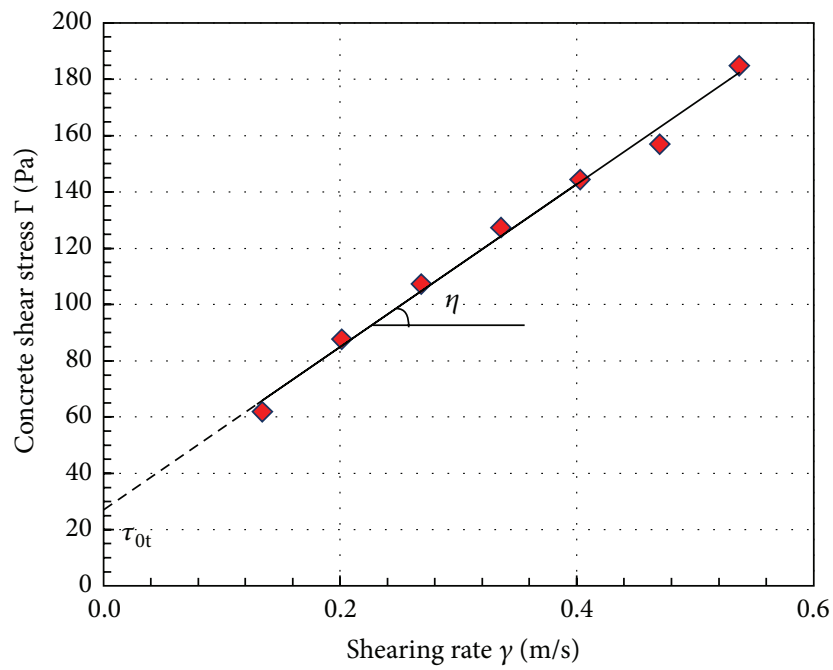

(b)

FIgURE 6: Example of tribometrical test result: (a) raw test result and (b) schematic view of concrete shear stress, shearing rate relation.

TABLE 1: 1st program: tested concretes' composition without superplasticizer.

\begin{tabular}{|c|c|c|c|c|c|c|c|c|}
\hline Concretes & $\mathrm{W} / \mathrm{C}$ & $\mathrm{A} / \mathrm{S}$ & $V_{\text {paste }}\left(\mathrm{m}^{3}\right)$ & Cement (kg) & Water $(\mathrm{kg})$ & Aggregates $(\mathrm{kg})$ & Sand $\left(\mathrm{m}^{3}\right)$ & Slump $(\mathrm{cm})$ \\
\hline \multicolumn{9}{|c|}{ Series 1: influence of cement paste volume $\left(V_{\text {paste }}\right)$} \\
\hline B11 & \multirow{4}{*}{0.5} & \multirow{4}{*}{1.2} & 0.378 & 460 & 230 & 848 & 706 & 21 \\
\hline B12 & & & 0.354 & 430 & 215 & 881 & 734 & 19 \\
\hline B13 & & & 0.329 & 400 & 200 & 915 & 763 & 15 \\
\hline B14 & & & 0.308 & 375 & 188 & 943 & 786 & 13 \\
\hline \multicolumn{9}{|c|}{ Series 2: influence of water/cement ratio (W/C) } \\
\hline B21 & 0.55 & \multirow{4}{*}{1.2} & \multirow{4}{*}{0.378} & 434 & 239 & \multirow{4}{*}{848} & \multirow{4}{*}{706} & 23 \\
\hline B22 & 0.5 & & & 460 & 230 & & & 21 \\
\hline B23 & 0.45 & & & 490 & 220 & & & 18 \\
\hline B24 & 0.4 & & & 524 & 210 & & & 11 \\
\hline \multicolumn{9}{|c|}{ Series 3: influence of aggregates/sand ratio (A/S) } \\
\hline B31 & \multirow{4}{*}{0.5} & 1 & \multirow{4}{*}{0.354} & \multirow{4}{*}{430} & \multirow{4}{*}{215} & 808 & 808 & 19 \\
\hline B32 & & 1.2 & & & & 881 & 734 & 19 \\
\hline B33 & & 1.4 & & & & 943 & 673 & 19 \\
\hline B34 & & 1.6 & & & & 994 & 621 & 19 \\
\hline \multicolumn{9}{|c|}{ Series 4: influence of aggregates diameter } \\
\hline \multicolumn{9}{|c|}{ Crushed ag. 4/12 } \\
\hline B41 & \multirow{2}{*}{0.5} & \multirow{2}{*}{1.2} & 0.378 & 460 & 230 & 868 & 723 & 19 \\
\hline B42 & & & 0.354 & 430 & 215 & 902 & 752 & 14 \\
\hline \multicolumn{9}{|c|}{ Crushed ag. 4/16 } \\
\hline $\mathrm{B} 1$ & \multirow{2}{*}{0.5} & \multirow{2}{*}{1.2} & 0.378 & 460 & 230 & 868 & 723 & 20 \\
\hline $\mathrm{B} 2$ & & & 0.354 & 430 & 215 & 902 & 752 & 15.5 \\
\hline \multicolumn{9}{|c|}{ Crushed ag. 4/20 } \\
\hline B43 & \multirow{3}{*}{0.5} & \multirow{3}{*}{1.2} & 0.378 & 460 & 230 & 868 & 723 & 21 \\
\hline B44 & & & 0.354 & 430 & 215 & 902 & 752 & 16 \\
\hline B45 & & & 0.329 & 400 & 200 & 936 & 780 & 10 \\
\hline \multicolumn{9}{|c|}{ Crushed ag. 10/20 } \\
\hline B11 & \multirow{4}{*}{0.5} & \multirow{4}{*}{1.2} & 0.378 & 460 & 230 & 848 & 706 & 21 \\
\hline B12 & & & 0.354 & 430 & 215 & 881 & 734 & 19 \\
\hline B13 & & & 0.329 & 400 & 200 & 915 & 762 & 15 \\
\hline B14 & & & 0.308 & 375 & 188 & 943 & 786 & 13 \\
\hline
\end{tabular}



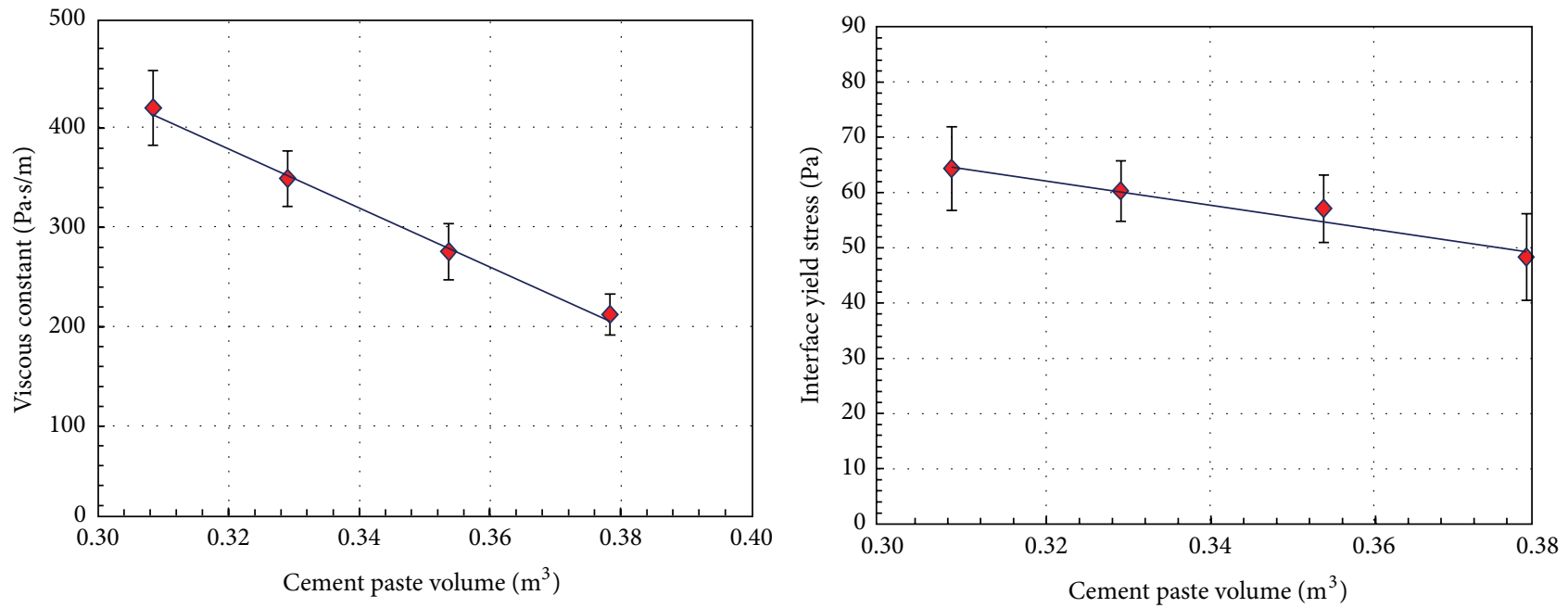

(a)
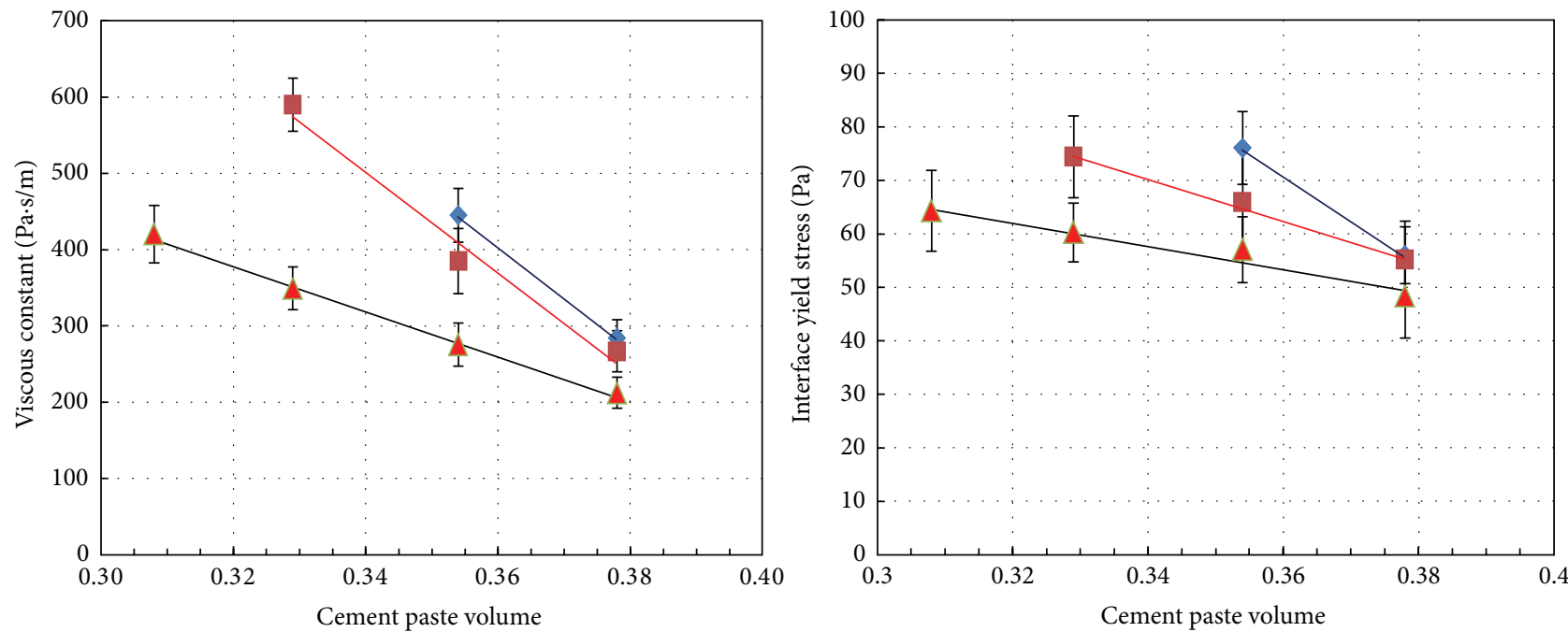

- Aggregate 4/12

- Aggregate 4/20

A Aggregate $10 / 20$

- Aggregate 4/12

- Aggregate $4 / 20$

A Aggregate $10 / 20$

(b)
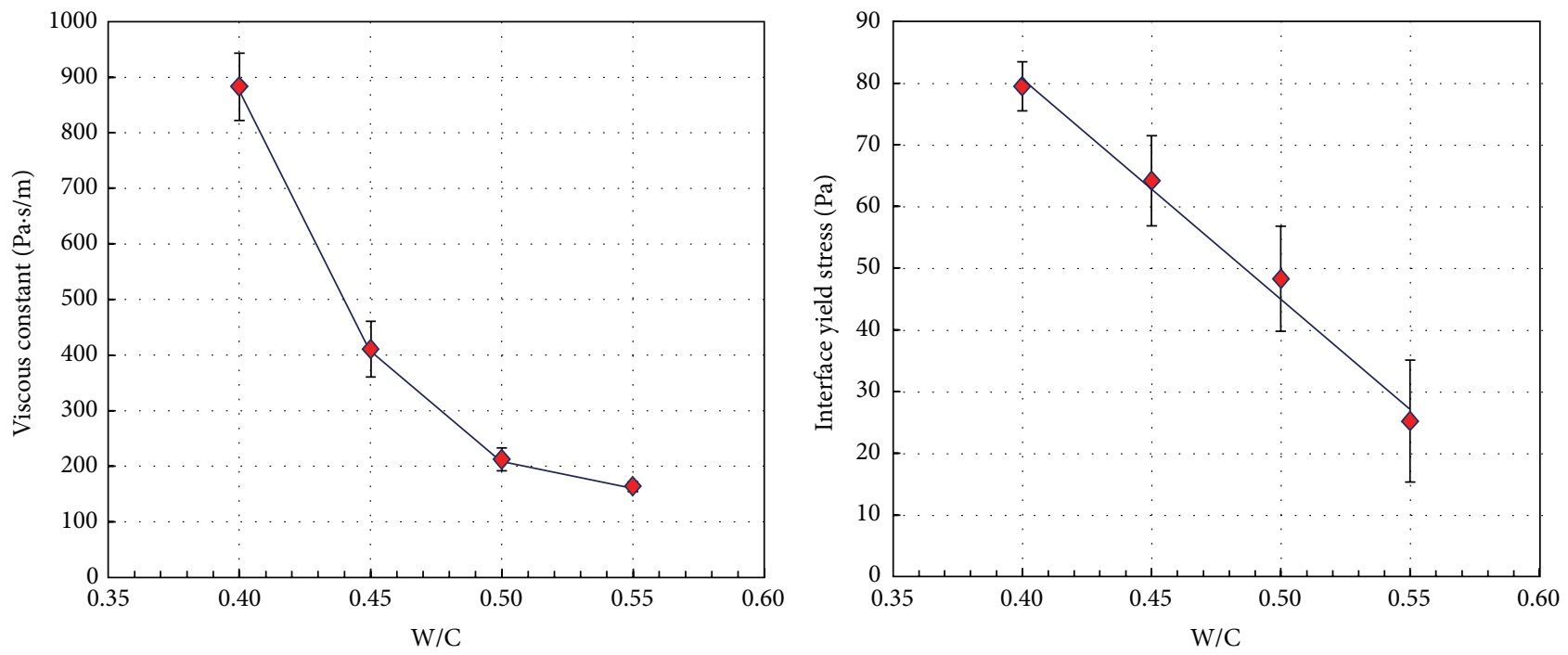

(c)

Figure 7: Continued. 

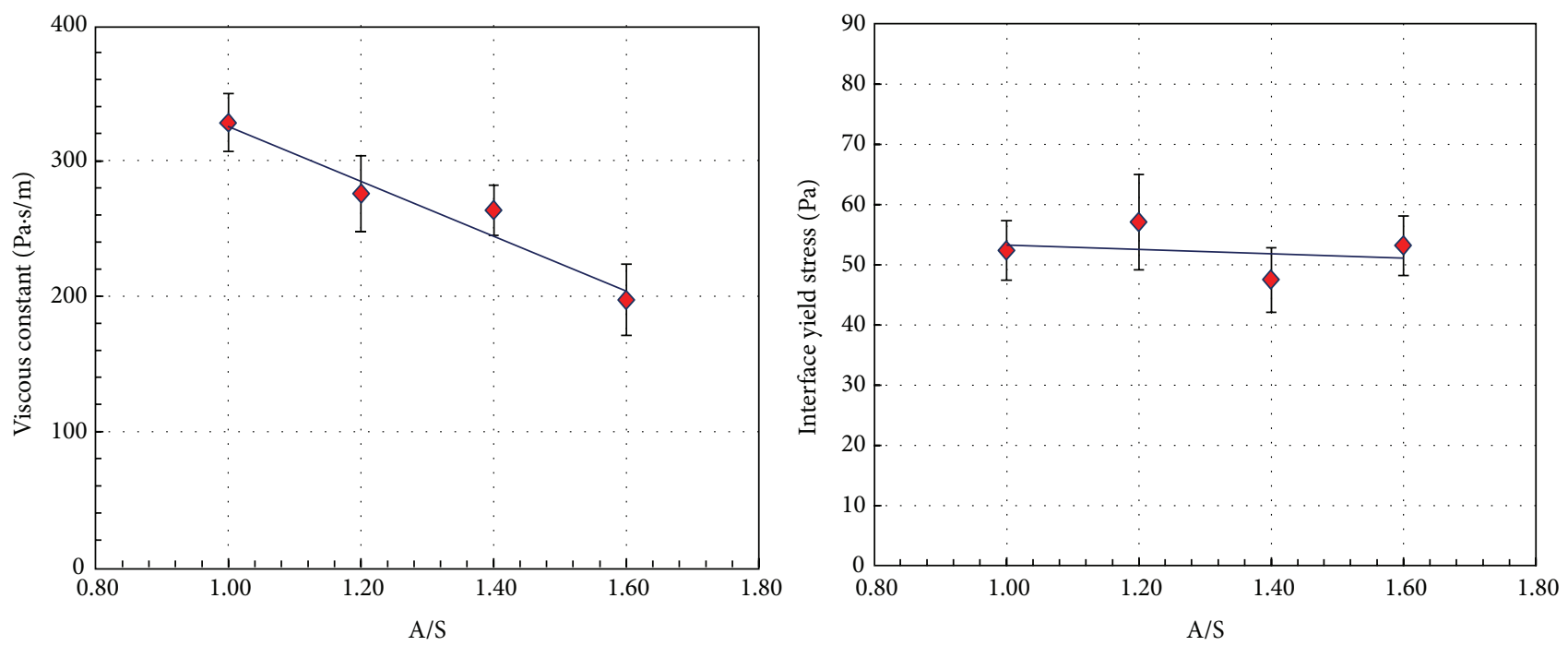

(d)

FiguRE 7: Experimental results of the first test program: (a) influence of the cement paste volume; (b) influence of the aggregates size; (c) influence of water/cement ratio; and (d) influence of aggregates/sand ratio.

which is based on clinker without additions. A granular skeleton is formed by regular concrete sand with grain-size distributions of $0 / 4 \mathrm{~mm}$ and different crushed aggregates for different grain-size distributions $(10 / 20,6 / 20,4 / 20$, and 4/12). All coarse aggregates and sand materials had specific gravities of 2.5. Five superplasticizers of two different natures were tested: four of the nature "polycarboxylate" and one of "phosphonate modified."

The studied mix proportions are collected in Tables 1 and 2. Table 1 corresponds to the first test program where all the tested concretes have been produced without superplasticizer. For every studied series in this program, in order to highlight effect of each composition parameter on the pumping parameters, only one formulation parameter was varied while keeping other parameters constant. The studied parameters are cement paste volume (series 1$)$, water/cement $(\mathrm{W} / \mathrm{C})$ ratio (series 2$)$, aggregates/sand $(\mathrm{A} / \mathrm{S})$ ratio (series 3 ), and influence of aggregates diameter (series 4). The concretes of the first three series have been mixed with the aggregates of size 10/20. For all the tested series, the studied formulation parameter was modified until the segregation of concrete keeping the concrete slumps higher than $10 \mathrm{~cm}$ that corresponds to the limit of the tribometrical test.

The composition of tested concretes in the second test program is gathered in Table 2 where one concrete composition has been tested with different type, dosage, and nature of superplasticizer.

In this test program, for each tested superplasticizer, the incorporated dosage is increased until apparition of segregation phenomenon in concrete.

2.4. Results and Analysis. The results of the first test program are summarized in Figure 7. Concerning the effect of the cement paste volume, Figures $7(\mathrm{a})$ and $7(\mathrm{~b})$ prove that the increase of the cement paste volume reduces the interface parameters whatever the used aggregates diameter. That promotes the concrete pumpability. The linear decrease of the viscous constant and of the interface yield stress can be explained by the augmentation of the interdistance between aggregate grains when the cement paste volume is more important. A higher interdistance favours the creation of the boundary layer at the interface concrete, wall of the pumping pipe as discussed by Ngo et al. [15, 20]. In the literature, this interdistance between aggregate gains $\left(E_{\max }\right)$ has been described by a model as proposed by de Larrard and Belloc [21] (see (8)). The model also shows that this interdistance depends not only on the maximal size of the aggregates gains but also on the compactness of the granular mixture which vary with the aggregate size range and the $\mathrm{A} / \mathrm{S}$ ratio in concretes. That explained for the result at Figure 7(b) where the interface parameters corresponding to different aggregate diameter are different even if the cement paste volume is the same.

It is already known that the $\mathrm{W} / \mathrm{C}$ ratio plays an important role in concrete plastic viscosity that influences the formation of the boundary layer at the interface and thus the interface friction. Figure $7(\mathrm{c})$ shows that the interface parameters decrease with the increase of the $\mathrm{W} / \mathrm{C}$ ratio keeping the same cement paste volume and A/S ratio. In fact, when the $\mathrm{W} / \mathrm{C}$ ratio increases, the cement paste of concrete is diluted and thus its plastic viscosity decreases. It promotes the formation of a boundary layer which is less viscous and thicker. Knowing that this layer is formed by cement, water, and sand fines particles comes from concrete during the test as discussed by Ngo et al. [15]. Consequently, a less viscous and thicker boundary layer reduces the interface friction and thus the interface parameters.

Concerning the $\mathrm{A} / \mathrm{S}$ ratio, the increase of this ratio, keeping the same $\mathrm{W} / \mathrm{C}$ ratio and the same cement paste 
TABLE 2: 2nd test program: tested concretes' composition with five superplasticizers of two different natures.

\begin{tabular}{|c|c|c|c|c|c|c|c|c|c|}
\hline Type of superplasticizer & Concretes & $\mathrm{W} / \mathrm{C}$ & $\mathrm{A} / \mathrm{S}$ & Sp (\%) & Cement (kg) & Water $(\mathrm{kg})$ & Aggregates 6/20 (kg) & Sand $(\mathrm{kg})$ & Slump $(\mathrm{cm})$ \\
\hline \multirow{5}{*}{ A1 (polycarboxylate modified) } & B1Ad.0 & \multirow{5}{*}{0.5} & \multirow{5}{*}{1.2} & 0 & \multirow{5}{*}{410} & \multirow{5}{*}{205} & \multirow{5}{*}{909.4} & \multirow{5}{*}{757.9} & 15 \\
\hline & B1Ad.0.2 & & & 0.2 & & & & & 17 \\
\hline & B1Ad.0.4 & & & 0.4 & & & & & 19 \\
\hline & B1Ad.0.6 & & & 0.6 & & & & & 20 \\
\hline & B1Ad.0.8 & & & 0.8 & & & & & 21 \\
\hline \multirow{4}{*}{ A2 (polycarboxylate modified) } & B1Ad.0 & \multirow{4}{*}{0.5} & \multirow{4}{*}{1.2} & 0 & \multirow{4}{*}{410} & \multirow{4}{*}{205} & \multirow{4}{*}{909.4} & \multirow{4}{*}{757.9} & 15 \\
\hline & B1Ad.0.2 & & & 0.2 & & & & & 17 \\
\hline & B1Ad.0.4 & & & 0.4 & & & & & 20 \\
\hline & B1Ad.0.45 & & & 0.45 & & & & & 21 \\
\hline \multirow{5}{*}{ A3 (phosphonate modified) } & B1Ad.0 & \multirow{5}{*}{0.5} & \multirow{5}{*}{1.2} & 0 & \multirow{5}{*}{410} & \multirow{5}{*}{205} & \multirow{5}{*}{909.4} & \multirow{5}{*}{757.9} & 15 \\
\hline & B1Ad.0.2 & & & 0.2 & & & & & 16 \\
\hline & B1Ad.0.4 & & & 0.4 & & & & & 19 \\
\hline & B1Ad.0.6 & & & 0.6 & & & & & 21 \\
\hline & B1Ad.0.8 & & & 0.8 & & & & & 22 \\
\hline \multirow{5}{*}{ A4 (polycarboxylate modified) } & B1Ad.0 & \multirow{5}{*}{0.5} & \multirow{5}{*}{1.2} & 0 & \multirow{5}{*}{410} & \multirow{5}{*}{205} & \multirow{5}{*}{909.4} & \multirow{5}{*}{757.9} & 15 \\
\hline & B1Ad.0.2 & & & 0.2 & & & & & 16 \\
\hline & B1Ad.0.4 & & & 0.4 & & & & & 19 \\
\hline & B1Ad.0.6 & & & 0.6 & & & & & 20 \\
\hline & B1Ad.0.8 & & & 0.8 & & & & & 22 \\
\hline \multirow{5}{*}{ A5 (polycarboxylate modified) } & B1Ad.0 & \multirow{5}{*}{0.5} & \multirow{5}{*}{1.2} & 0 & \multirow{5}{*}{410} & & & & 15 \\
\hline & B1Ad.0.2 & & & 0.2 & & & & & 16 \\
\hline & B1Ad.0.4 & & & 0.4 & & 205 & 909.4 & 757.9 & 18 \\
\hline & B1Ad.0.6 & & & 0.6 & & & & & 21 \\
\hline & B1Ad.0.8 & & & 0.8 & & & & & 24 \\
\hline
\end{tabular}

volume, reduces the quantity of sand in concrete as shown in Table 1 (series 3). Therefore, the boundary layer is formed with less fine particles which proceed from the sand of concrete. It diminishes the viscous constant when the A/S ratio increases (see Figure $7(\mathrm{~d})$ ). Nevertheless, the interface yield stress is not so sensitive with the variation of the A/S ratio. That is probably due to the concrete slump which does not change when the A/S varies (see Table 2). More explanation for this phenomenon is provided in Section 4.

As expected, the second test program is intended to demonstrate effects of superplasticizer and its nature on interface parameters. Results of this test program are summarized in Figures 8 and 9. We already know that the addition of superplasticizer in concrete improves its fluidity and hence an augmentation of the concrete slump. Figure 8 represents the evolution of the interface yield stress with the concrete slump. The result shows that, for all the tested superplasticizer, the interface yield stress decreases when the dosage of superplasticizer increases.

Figure 9 gathers all the results corresponding to different tested superplasticizers. The result proves that the interface yield stress also varies with the type of superplasticizer.

The decrease of the interface yield stress according to the augmentation of the superplasticizer dosage can be explained by the fact that the increase of the superplasticizer dosage fluidifies the cement paste of concrete keeping the cement paste volume and the interdistance between aggregates constant.
That induces the formation of a more fluid boundary layer which results in a reduction of the interface yield stress.

\section{Interface Yield Stress Model and Prediction of the Pumping Pressure from Concrete Formulation}

3.1. Construction of the Interface Yield Stress Model. To build the interface yield stress model, there are two possibilities: the first is to base on characteristics of the boundary layer and its thickness: this possibility is very difficult to realize in practice because there is not actually any exact method to measure its thickness and to calculate exactly the boundary layer composition from concrete composition; the second is to base directly on the concrete composition parameters. This possibility seems to be easier to realize in practice. So, in this paper, these authors try to build the interface yield stress model directly from the concretes composition parameters in using the experimental results presented above.

Basing on these results, we can adopt a hypothesis that the interface yield stress varies with the concrete slump whatever tested concretes with or without superplasticizer. In addition, in the literature, many authors have shown that the concrete slump determines the concrete yield stress $\tau_{0}$ (Pa) as discussed elsewhere [24, 26-28]. Proposed models 

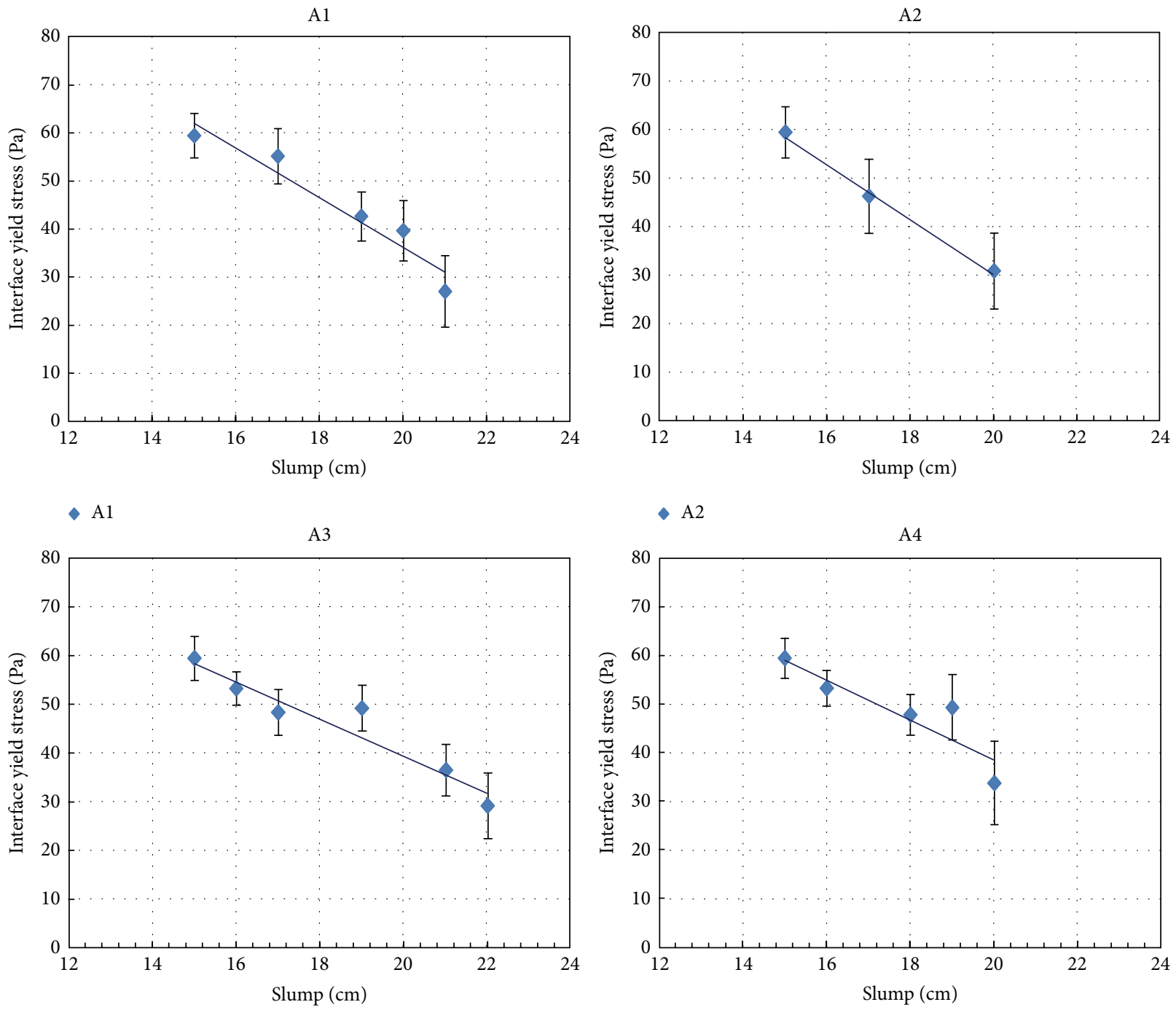

- A3

- A4

A5

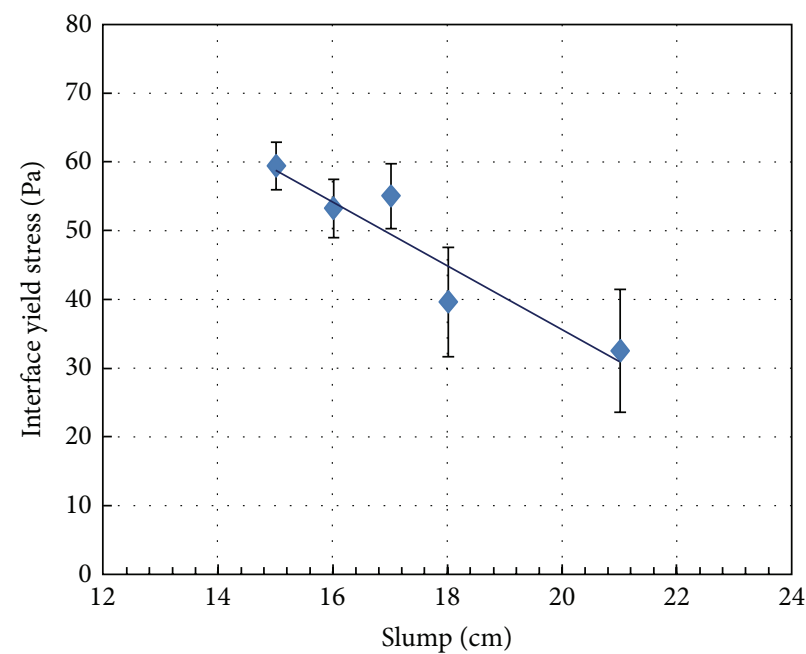

FIgURE 8: Experimental results of the second test program. 
TABLE 3: (a) Comparison between the interface yield stress calculated by the model and that measured by the tribometer in the first test program. (b) Comparison between the interface yield stress calculated by the model and that measured by the tribometer in the second test program.

(a)

\begin{tabular}{|c|c|c|c|c|c|c|c|c|}
\hline Concretes & $\mathrm{W} / \mathrm{C}$ & $\mathrm{A} / \mathrm{S}$ & $V_{\text {paste }}\left(\mathrm{m}^{3}\right)$ & Slump $(\mathrm{cm})$ & $\eta_{\text {exp. }}(\mathrm{Pa} \cdot \mathrm{s} / \mathrm{m})$ & $\tau_{0 t \exp .}(\mathrm{Pa})$ & $\eta_{\text {modele }}(\mathrm{Pa} \cdot \mathrm{s} / \mathrm{m})$ & $\tau_{0 t \text { modele }}(\mathrm{Pa})$ \\
\hline \multicolumn{9}{|c|}{ Series 1: influence of cement paste volume $\left(V_{\text {paste }}\right)$} \\
\hline B11 & \multirow{4}{*}{0.5} & \multirow{4}{*}{1.2} & 0.378 & 21 & 212.3 & 48.3 & 229.2 & 43.9 \\
\hline B12 & & & 0.354 & 19 & 275.6 & 57.1 & 276.5 & 50.2 \\
\hline $\mathrm{B} 13$ & & & 0.329 & 15 & 349.1 & 60.3 & 385.6 & 62.9 \\
\hline B14 & & & 0.308 & 13 & 420.4 & 64.3 & 481.6 & 69.3 \\
\hline \multicolumn{9}{|c|}{ Series 2: influence of water/cement ratio (W/C) } \\
\hline B21 & 0.55 & \multirow{4}{*}{1.2} & \multirow{4}{*}{0.378} & 23 & 163.6 & 25.2 & 168.1 & 37.5 \\
\hline B22 & 0.5 & & & 21 & 212.3 & 48.3 & 229.2 & 43.9 \\
\hline B23 & 0.45 & & & 18 & 411.0 & 64.2 & 376.3 & 53.4 \\
\hline B24 & 0.4 & & & 11 & 882.8 & 79.5 & 917.0 & 75.6 \\
\hline \multicolumn{9}{|c|}{ Series 3: influence of aggregates/sand ratio (A/S) } \\
\hline B31 & \multirow{4}{*}{0.5} & 1 & \multirow{4}{*}{0.354} & 19 & 328.1 & 52.4 & 283.9 & 50.2 \\
\hline B32 & & 1.2 & & 19 & 275.6 & 57.1 & 276.5 & 50.2 \\
\hline B33 & & 1.4 & & 19 & 263.5 & 47.5 & 271.9 & 50.2 \\
\hline B34 & & 1.6 & & 19 & 197.2 & 53.2 & 269.0 & 50.2 \\
\hline \multicolumn{9}{|c|}{ Series 4: influence of aggregates diameter } \\
\hline \multicolumn{9}{|c|}{ Crushed ag. 4/12 } \\
\hline B41 & \multirow{2}{*}{0.5} & \multirow{2}{*}{1.2} & 0.378 & 19 & 283.9 & 56.0 & 303.4 & 50.2 \\
\hline B42 & & & 0.354 & 14 & 445.0 & 76.1 & 447.3 & 66.1 \\
\hline \multicolumn{9}{|c|}{ Crushed ag. 4/20 } \\
\hline B43 & \multirow{3}{*}{0.5} & \multirow{3}{*}{1.2} & 0.378 & 21 & 266.5 & 55.2 & 228.3 & 43.9 \\
\hline B44 & & & 0.354 & 16 & 385.2 & 65.9 & 326.9 & 59.8 \\
\hline B45 & & & 0.329 & 10 & 590.2 & 74.4 & 574.8 & 78.8 \\
\hline \multicolumn{9}{|c|}{ Crushed ag. 10/20 } \\
\hline B11 & \multirow{4}{*}{0.5} & \multirow{4}{*}{1.2} & 0.378 & 21 & 212.3 & 48.3 & 229.2 & 43.9 \\
\hline $\mathrm{B} 12$ & & & 0.354 & 19 & 275.6 & 57.1 & 276.5 & 50.2 \\
\hline $\mathrm{B} 13$ & & & 0.329 & 15 & 349.1 & 60.3 & 385.6 & 62.9 \\
\hline B14 & & & 0.308 & 13 & 420.4 & 64.3 & 481.6 & 69.3 \\
\hline
\end{tabular}

(b)

\begin{tabular}{|c|c|c|c|c|c|c|c|c|}
\hline Type of superplasticizer & Concretes & $\mathrm{W} / \mathrm{C}$ & $\mathrm{A} / \mathrm{S}$ & Sp (\%) & Slump $(\mathrm{cm})$ & $\eta_{\text {exp. }}(\mathrm{Pa} \cdot \mathrm{s} / \mathrm{m})$ & $\tau_{0 t \exp }(\mathrm{Pa})$ & $\tau_{0 t \text { model }}(\mathrm{Pa})$ \\
\hline \multirow{5}{*}{ A1 (polycarboxylate modified) } & B1Ad.0 & \multirow{5}{*}{0.5} & \multirow{5}{*}{1.2} & 0 & 15 & 464.5 & 59.4 & 62.9 \\
\hline & B1Ad.0.2 & & & 0.2 & 17 & 483.2 & 55.2 & 53.1 \\
\hline & B1Ad.0.4 & & & 0.4 & 19 & 452.9 & 42.6 & 43.2 \\
\hline & B1Ad.0.6 & & & 0.6 & 20 & 423.9 & 39.7 & 36.6 \\
\hline & B1Ad.0.8 & & & 0.8 & 21 & 289.0 & 27.0 & 29.9 \\
\hline \multirow{4}{*}{ A2 (polycarboxylate modified) } & B1Ad.0 & \multirow{4}{*}{0.5} & \multirow{4}{*}{1.2} & 0 & 15 & 464.5 & 59.4 & 62.9 \\
\hline & B1Ad.0.2 & & & 0.2 & 17 & 445.8 & 46.2 & 49.6 \\
\hline & B1Ad.0.4 & & & 0.4 & 20 & 427.2 & 30.8 & 33.1 \\
\hline & B1Ad.0.45 & & & 0.45 & 21 & 403.9 & 33.0 & 28.1 \\
\hline \multirow{5}{*}{ A3 (phosphonate modified) } & B1Ad.0 & \multirow{5}{*}{0.5} & \multirow{5}{*}{1.2} & 0 & 15 & 464.5 & 59.4 & 62.9 \\
\hline & B1Ad.0.2 & & & 0.2 & 16 & 456.5 & 53.2 & 56.3 \\
\hline & B1Ad.0.4 & & & 0.4 & 19 & 477.7 & 49.2 & 43.2 \\
\hline & B1Ad.0.6 & & & 0.6 & 21 & 385.0 & 36.5 & 33.4 \\
\hline & B1Ad.0.8 & & & 0.8 & 22 & 372.3 & 29.2 & 26.7 \\
\hline
\end{tabular}


(b) Continued.

\begin{tabular}{lcccccccc}
\hline Type of superplasticizer & Concretes & W/C & A/S & Sp $(\%)$ & Slump $(\mathrm{cm})$ & $\eta_{\text {exp. }}(\mathrm{Pa} \cdot \mathrm{s} / \mathrm{m})$ & $\tau_{0 \text { texp. }}(\mathrm{Pa})$ & $\tau_{0 t \mathrm{model}}(\mathrm{Pa})$ \\
\hline & B1Ad.0 & & & 0 & 15 & 464.5 & 59.4 & 62.9 \\
& B1Ad.0.2 & & & 0.2 & 16 & 456.5 & 53.2 & 55.1 \\
A4 (polycarboxylate modified) & B1Ad.0.4 & 0.5 & 1.2 & 0.4 & 19 & 440.4 & 54.3 & 40.9 \\
& B1Ad.0.6 & & & 0.6 & 20 & 447.4 & 33.7 & 33.1 \\
& B1Ad.0.8 & & 0.8 & 22 & 282.5 & 17.4 & 22.1 \\
\hline & B1Ad.0 & & 0 & 15 & 464.5 & 59.4 & 62.9 \\
A5 (polycarboxylate modified) & B1Ad.0.2 & & & 0.2 & 16 & 456.5 & 53.2 & 56.3 \\
& B1Ad.0.4 & 0.5 & 1.2 & 0.4 & 18 & 409.1 & 39.6 & 46.4 \\
& B1Ad.0.6 & & & 0.6 & 21 & 394.4 & 32.5 & 33.4 \\
& B1Ad.0.8 & & & 0.8 & 24 & 274.2 & 10.2 & 20.4 \\
\hline
\end{tabular}

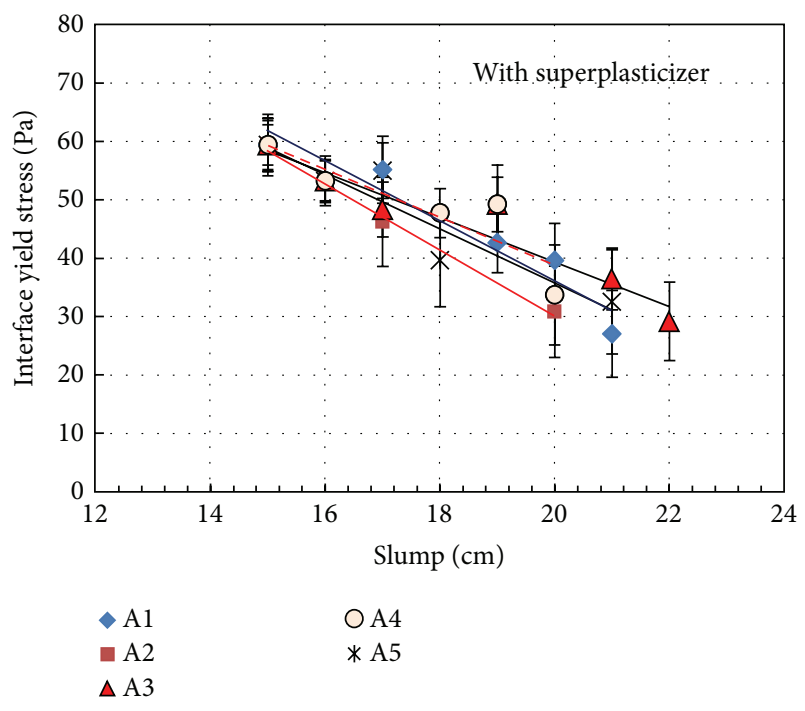

Figure 9: Variation of the interface yield stress according to the concrete slump.

to calculate the concrete yield stress and relate these two parameters are as follows.

Murata and Kikukawa [26]:

$$
\tau_{0}=714-473 \log \left(\frac{\mathrm{Sl}}{10}\right) .
$$

Hu et al. [27]:

$$
\tau_{0}=\frac{\rho_{\mathrm{sg}}}{0.27}(300-\mathrm{Sl}) .
$$

Ferraris and de Larrard [28]:

$$
\tau_{0}=\frac{(300-\mathrm{Sl}) \cdot \rho_{\mathrm{sg}}}{0.347}+212 .
$$

Wallevik [24]:

$$
\mathrm{Sl}=300-0.347 \frac{\left(\tau_{0}+394\right)}{\rho_{\mathrm{sg}}}+\alpha\left(\tau_{0}-\tau_{0}^{\mathrm{ref}}\right)\left(V_{m}-V_{m}^{\mathrm{ref}}\right)
$$

where $\tau_{0}$ is static yield stress of concrete. $\rho_{\text {ref }}$ is density of water ( $\rho_{\text {ref }}=1000 \mathrm{~kg} / \mathrm{m}^{3}$ at $4^{\circ} \mathrm{C}$ ), Sl is concrete slump, $\alpha=$
$7.7 \cdot 10^{-3} \mathrm{~mm} /(\mathrm{Pa} \cdot \mathrm{l}), \rho$ is density of concrete, $\tau_{0}^{\mathrm{ref}}=200 \mathrm{~Pa}, \rho_{\mathrm{sg}}$ is specific gravity $\left(\rho_{\mathrm{sg}}=\rho / \rho_{\text {ref }}\right), V_{m}$ is fraction of volume of cementitious matrix $\left(1 / \mathrm{m}^{3}\right)$, and $V_{m}^{\mathrm{ref}}=345 \mathrm{l} / \mathrm{m}^{3}$.

Therefore, it is interesting to represent the relation between the interface yield stress and the concrete yield stress because the variation gap of the yield stress is much more important (so more sensitive) than that of the concrete slump. Keeping in mind that the interface yield stress probably has a rigorous relation with the concrete yield stress, Figures 10, 11,12 , and 13 present the evolution of the interface yield stress $\left(\tau_{0 t}\right)$ according to the yield stress $\left(\tau_{0}\right)$ calculated in using these four proposed models represented by (11)-(14).

In comparing the regression coefficient $\left(R^{2}\right)$ of the trend line corresponding to the evolution of the interface yield stress according to the concrete yield stress calculated by the 4 models, (13) has been chosen, because this model permits to have the best $R^{2}$ of the regression line with the two tested concretes series (series 1 with superplasticizer and series 2 without superplasticizer) (see Figure 12).

When comparing Figure 12(a) with Figure 12(b), we can observe that, with the same concrete yield stress, the concrete with superplasticizer has a smaller interface yield stress in comparing to that without superplasticizer. This remark confirms the experimental results presented above that the interface yield stress depends also on the dosage and the nature of superplasticizer. Hence, the form of the interface yield stress model is proposed as follows:

$$
\tau_{0 t}=k_{1} \cdot \tau_{0}+k_{2}-k_{3} \cdot \frac{\mathrm{Sp}}{\mathrm{Sp}^{*}}
$$

where $k_{1} ; k_{2}(\mathrm{~Pa})$, and $k_{3}(\mathrm{~Pa})$ are experimental parameters to adjust and $\mathrm{Sp}$ and $\mathrm{Sp}^{*}$ (in \%) are, respectively, the dosage and the saturation dosage of superplasticizer.

To adjust the parameters $k_{1}$ and $k_{2}$, the experimental results corresponding to the first test program (without superplasticizer) have been used. The authors then keep these parameters constant to adjust the parameter $k_{3}$ using the experimental results of the second test program (with superplasticizer). By using the method of minimizing sum squared error to adjust these parameters from the measurements, the 


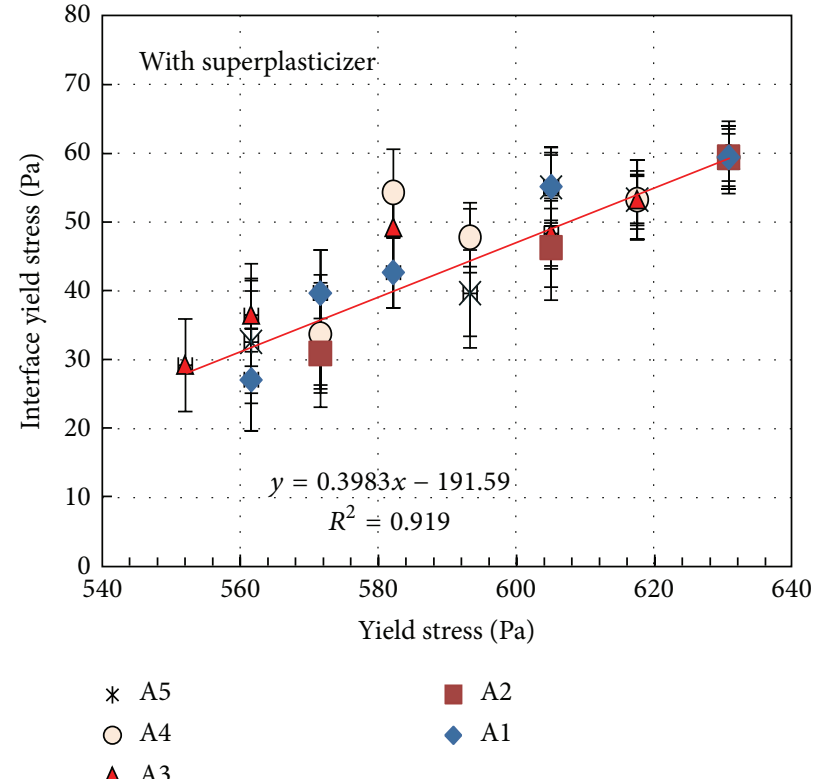

(a)

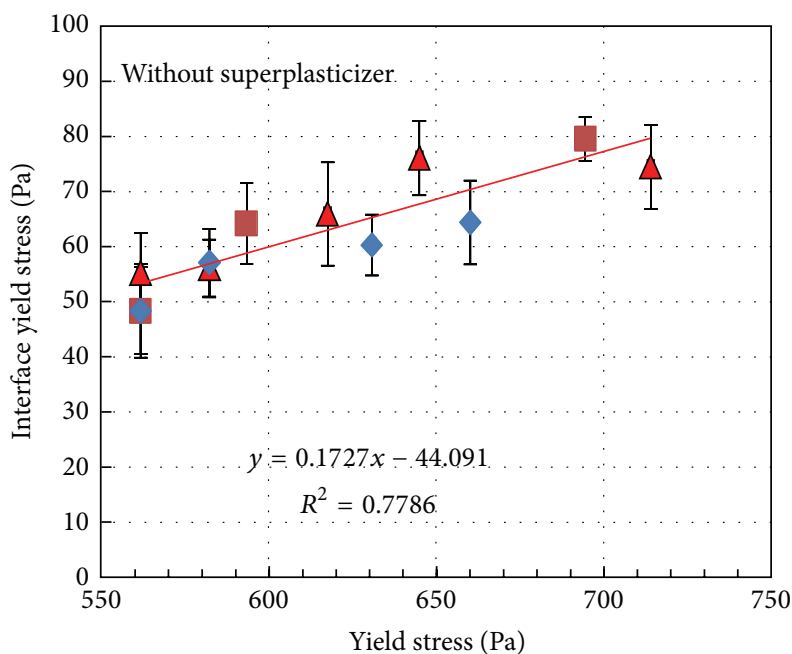

$\Delta$ Aggregates diameter
W/C
$V_{\text {paste }}$

(b)

FIGURE 10: Evolution of the interface yield stress $\tau_{0 t}$ according to the concrete yield stress $\tau_{0}$ calculated by (11): (a) concretes series without superplasticizer and (b) concretes series with superplasticizer.

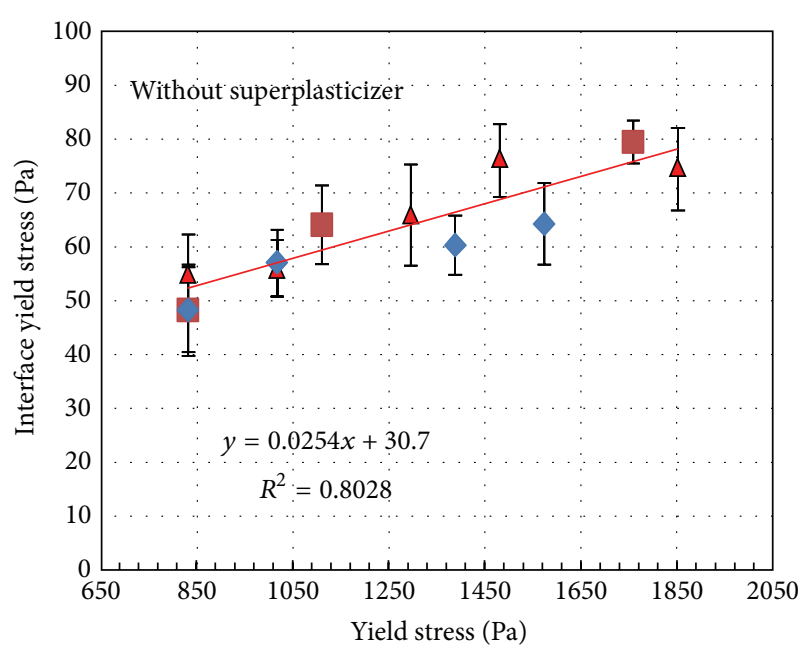

$\Delta$ Aggregates diameter

- W/C

- $V_{\text {paste }}$

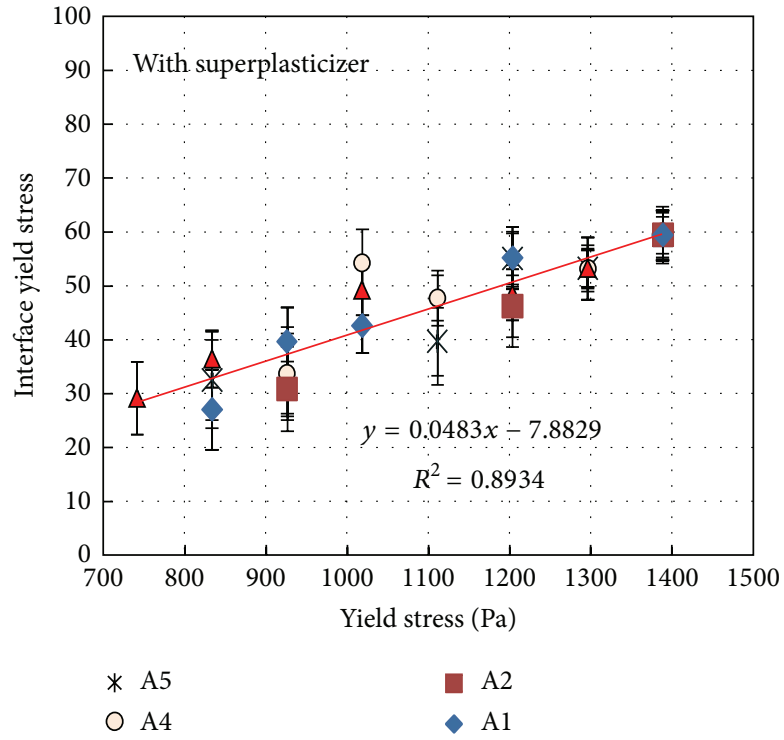

$\triangle \mathrm{A} 3$

(a)

(b)

FIGURE 11: Evolution of the interface yield stress $\tau_{0 t}$ according to the concrete yield stress $\tau_{0}$ calculated by (12): (a) concretes series without superplasticizer and (b) concretes series with superplasticizer.

authors thus propose the interface yield stress model as in the following equation:

$$
\tau_{0 t}=0.045 \tau_{0}+6-14 \frac{\mathrm{Sp}}{\mathrm{Sp}^{*}}(\text { in } \mathrm{Pa})
$$

3.2. Validation of the Interface Yield Stress Model. Table 3(a, b) and Figures 14 and 15 represent the comparison between the interface yield stress calculated by the model and that measured with the tribometer. The result shows that the model can predict well the interface yield stress and its evolution tendency when the concrete composition parameters 


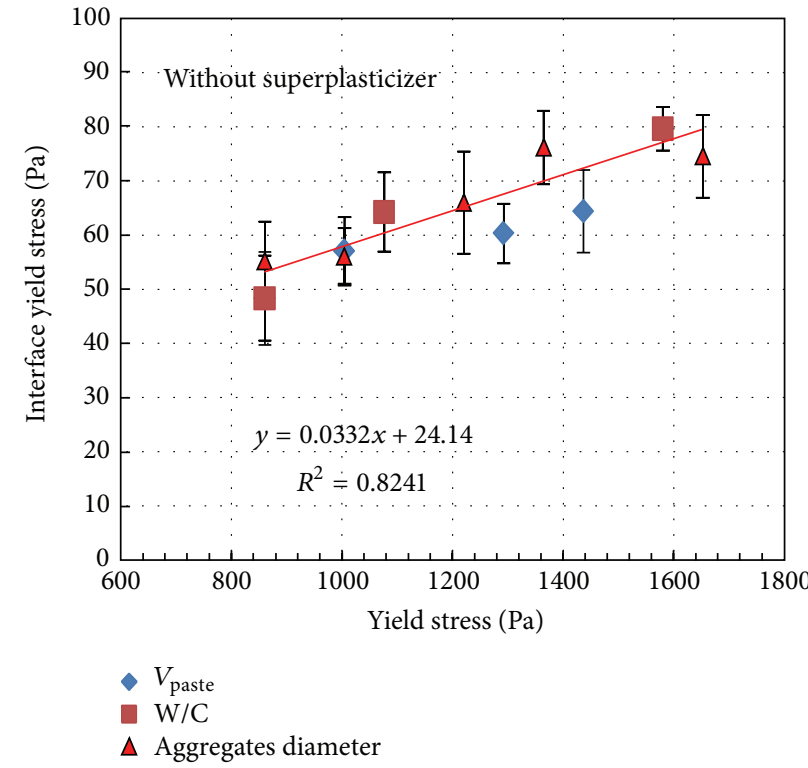

(a)

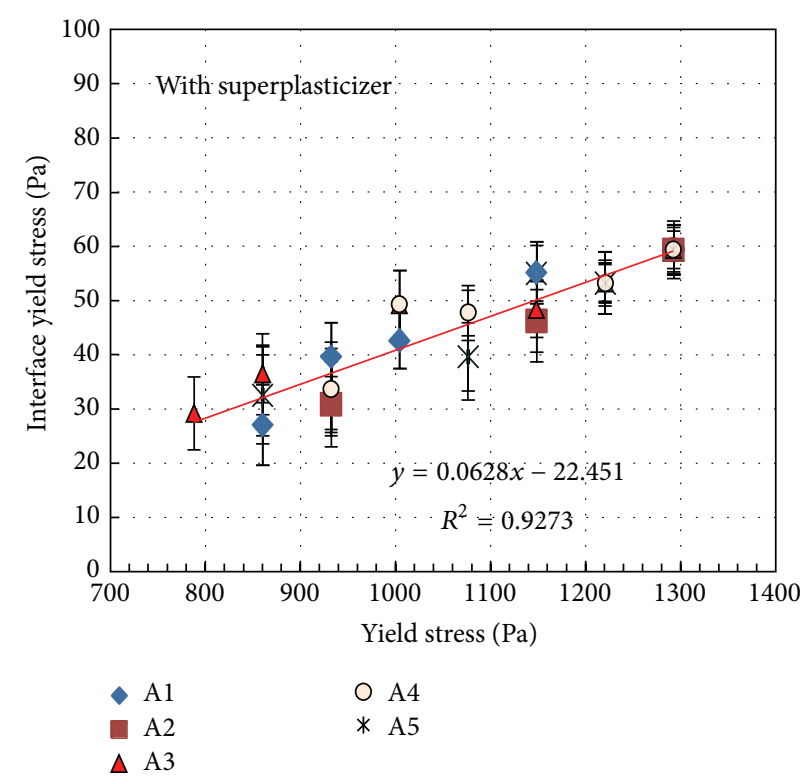

(b)

FIGURE 12: Evolution of the interface yield stress $\tau_{0 t}$ according to the concrete yield stress $\tau_{0}$ calculated by (13): (a) concretes series without superplasticizer and (b) concretes series with superplasticizer.

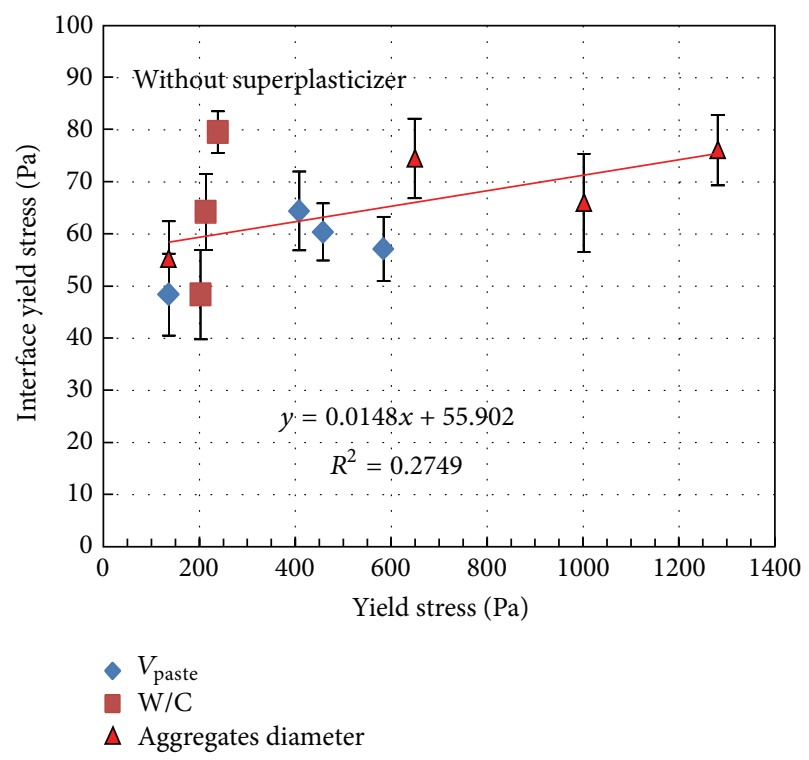

(a)

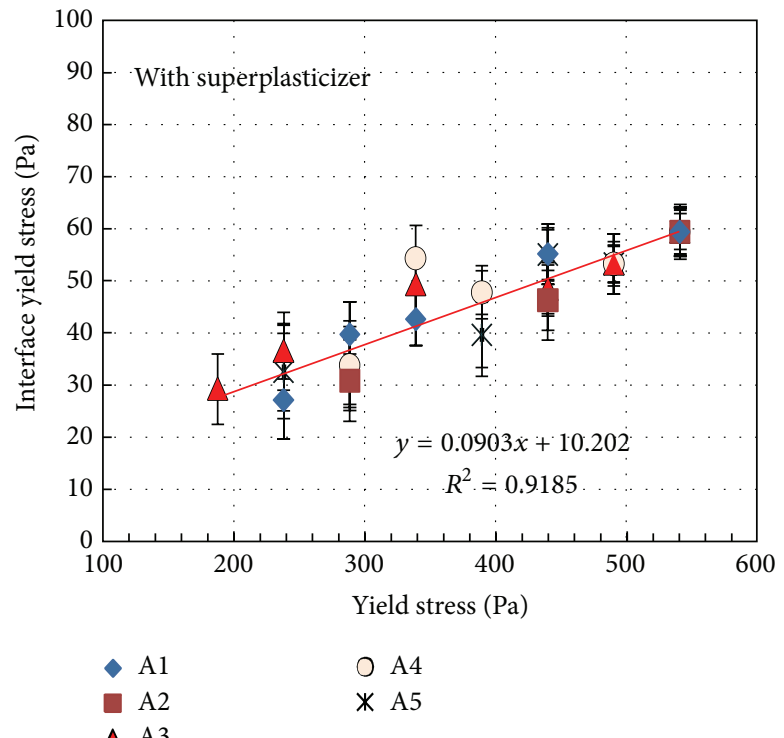

(b)

FIGURE 13: Evolution of the interface yield stress $\tau_{0 t}$ according to the concrete yield stress $\tau_{0}$ calculated by (14): (a) concretes series without superplasticizer and (b) concretes series with superplasticizer.

vary. The surrounded point in Figure 14 corresponds to the segregated concrete whose $\mathrm{W} / \mathrm{C}$ ratio is equal to 0.55 .

The interface yield stress calculated by the model and that measured by the tribometer corresponding to all the tested concretes have been then compared in Figure 15.

The result shows that most of the experimental points are located around the line " $y=x$." It means that the model can very well predict the measurements. The calculated error of the present model is less than $\pm 13 \%$.

\subsection{Prediction of the Pumping Pressure from Concrete Formu-} lation. In this part, the authors propose a method to estimate the pumping pressure from tribometrical parameters determined by using the two proposed models $\left(\eta\right.$ model and $\tau_{0 t}$ 

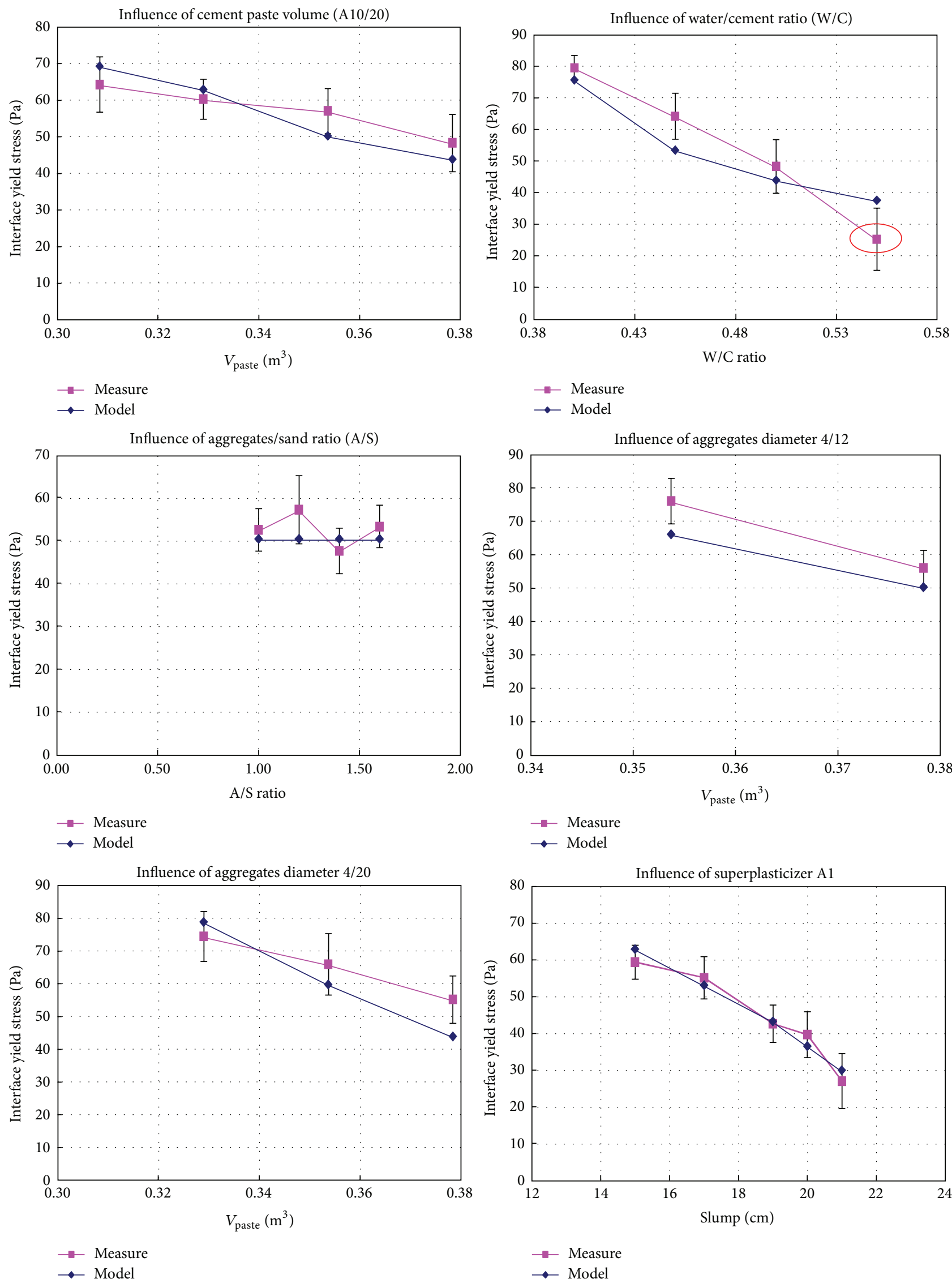

FIgURE 14: Continued. 

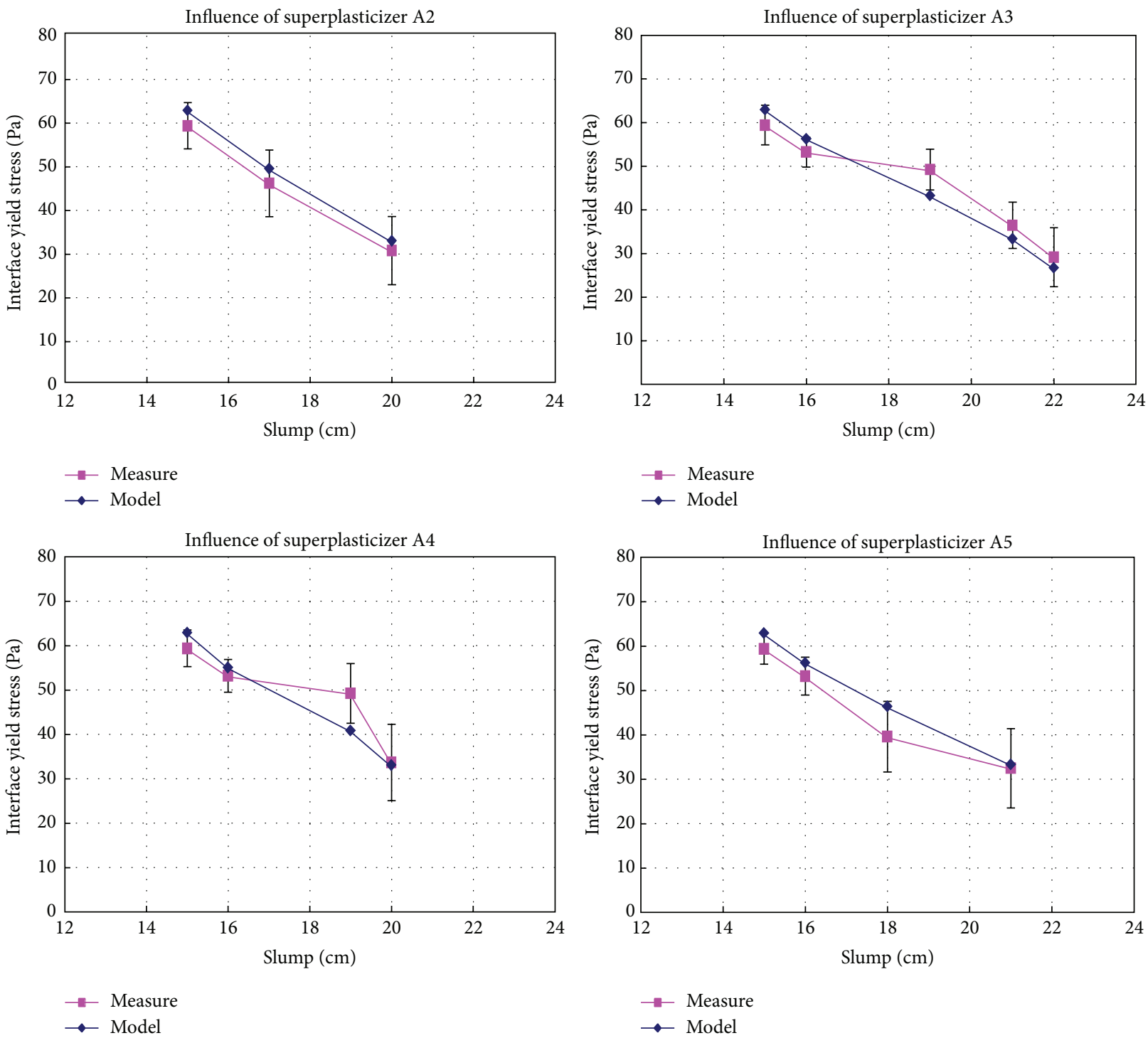

FIGURE 14: Comparison between the interface yield stress calculated by the model and the measurements.

model) and a pumping pressure model as shown in (2). In order to validate the method, tested concretes compositions in the study of Kaplan have been chosen. For each concrete formulation, the pumping pressure will be calculated directly from concrete composition using the two interface parameters models ( $\eta$ model and $\tau_{0 t}$ model) without tribometrical measurements. This pressure is compared with the pressure obtained using Kaplan' tribometrical measurements as well as with the real pressure measured with pumps on the building site. The diagram of the comparison is presented in Figure 2.

The following hypotheses have been used in this study: the pumping flow is equal to $25 \mathrm{~m}^{3} / \mathrm{h}$; the diameter of the pumping pipe is equal to $125 \mathrm{~mm}$; and the filling factor $\left(k_{r}\right)$ is equal to 0.8 .

Tested concretes compositions in the study of Kaplan are collected in Table 4.

The comparison results presented in Figure 16 show that the two calculation methods give nearly the same results.
Thus, the authors can conclude that, using these authors' models ( $\eta$ model and $\tau_{0 t}$ model) and the pumping pressure model, the pumping pressure can be calculated directly from concrete composition with a satisfactory precision of approximately $15 \%$.

\section{Conclusions}

The important role of the interface parameters $\left(\tau_{0 t}\right.$ and $\eta$ ) on the pumping pressure was clearly proved in the present study. Abovementioned tribometer developed by Ngo [18] has been used by the authors in order to investigate the variation of the interface yield stress $\left(\tau_{0 t}\right)$ according to the concrete composition parameters.

The results of the first test program allow the following conclusions to be drawn.

(i) With all the grain-size distributions of the used aggregates, the increase of the cement paste volume 


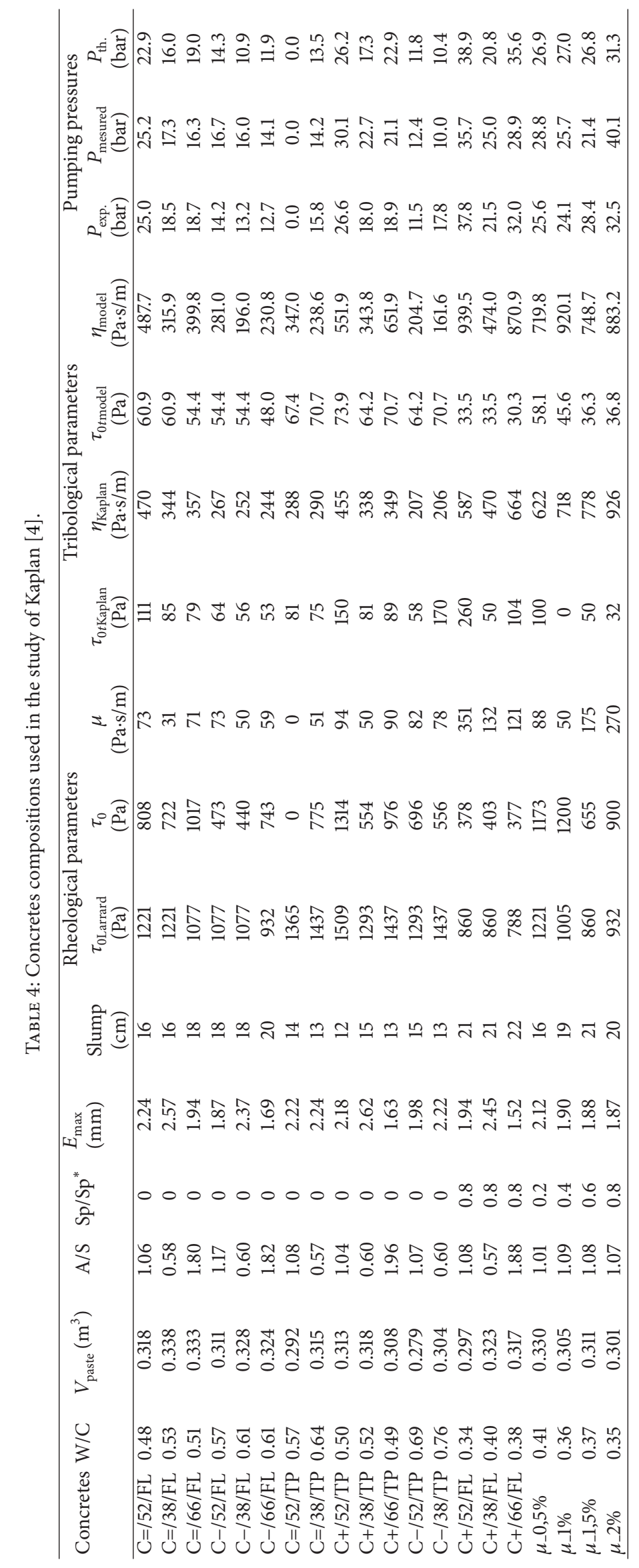




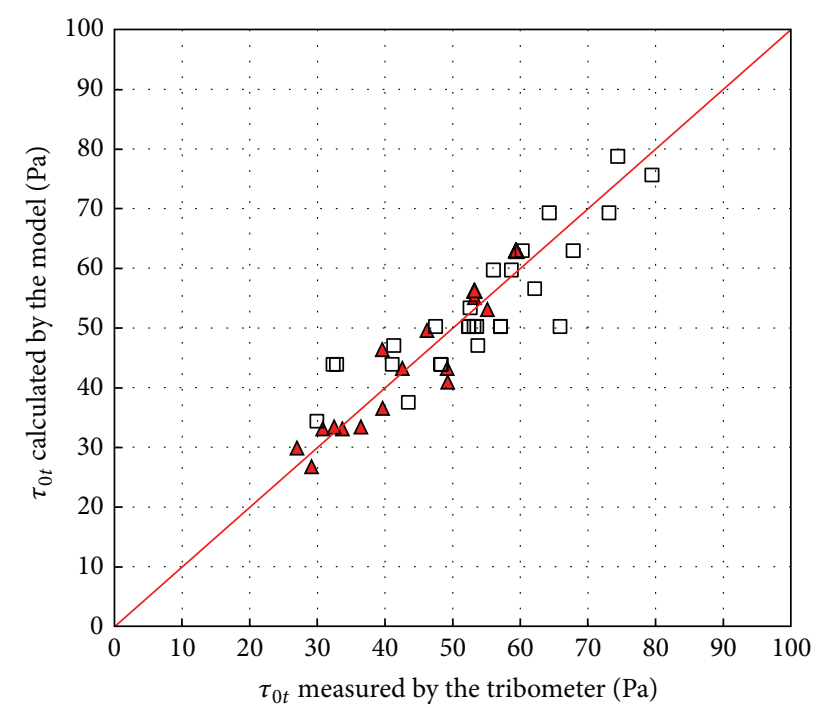

$\Delta \quad$ Model versus measurement (with superplasticizer)

$\square \quad$ Model versus measurement (without superplasticizer) Linear $(y=x)$

FIGURE 15: Validation of the model with the measurements.

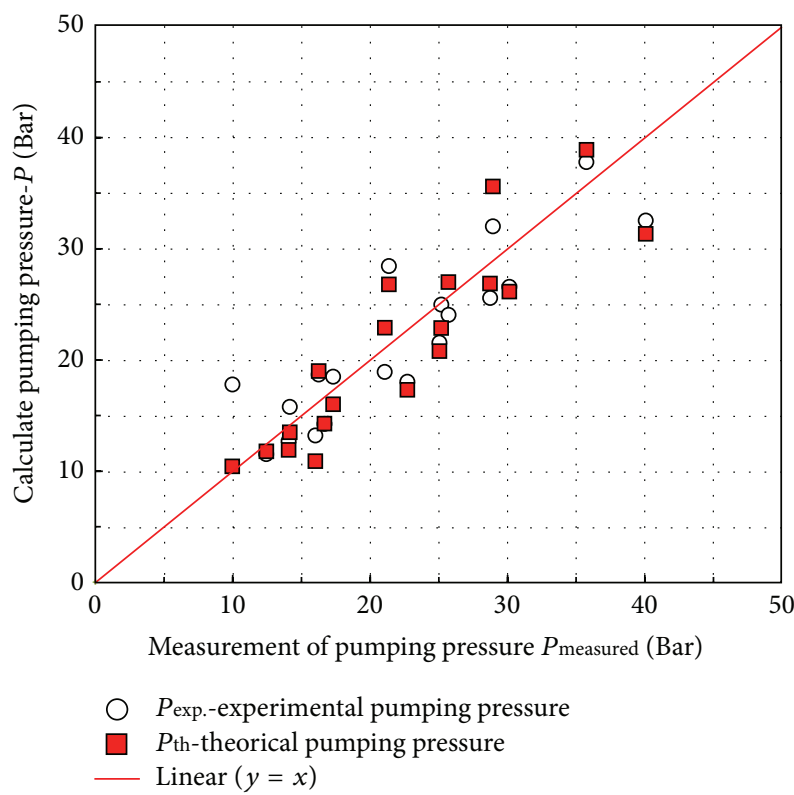

FIGURE 16: Comparison of the pumping pressure calculated using the authors' models ( $\eta$ model and $\tau_{0 t}$ model) and that calculated using measurements of Kaplan.

reduces the interface friction. It is confirmed by the linear decrease of the viscous constant and of the interface yield stress.

(ii) When the $\mathrm{W} / \mathrm{C}$ ratio increases, the viscous constant and the interface yield stress decrease following two different tendencies. The interface yield stress decreases linearly with the rise of the $\mathrm{W} / \mathrm{C}$ ratio. However, the viscous constant reduces significantly following a nonlinear function when the $\mathrm{W} / \mathrm{C}$ ratio increases.

(iii) The increase of the $\mathrm{A} / \mathrm{S}$ ratio results in a linear reduction of the viscous constant, whereas the interface yield stress is not so sensitive with the variation of the $\mathrm{A} / \mathrm{S}$ ratio because there is a relation between this parameter and the concrete yield stress, which does not vary when the slump of the tested concrete is constant (see the proposed interface yield stress model).

The results of the second test program allow concluding that, with all the tested superplasticizer, the interface yield stress decreases with the increase of the superplasticizer dosage and it varies with the type and the nature of superplasticizer. The results also prove that the interface yield stress decreases when the concrete slump increases by addition of superplasticizer.

The authors proposed in this paper a method to calculate directly the pumping pressure from ordinary concrete composition without measurements of the pumping parameters. This method is based on the pumping pressure model of Kaplan et al. [4,5] and the following two models: the viscous constant model $(\eta)$ proposed by Ngo et al. [10] and the interface yield stress model $\left(\tau_{0 t}\right)$. The latter is proposed and validated in this paper with authors' experimental results. The calculated error of the present model is less than $\pm 13 \%$.

The comparison of the pumping pressure calculated using these authors' models ( $\eta$ model and $\tau_{0 t}$ model) and that calculated thanks to Kaplan' tribometrical measurements as well as with the real pressure measured with pumps on the building site permits to conclude that the pumping pressure can be calculated directly from concrete composition with a satisfactory precision of approximately $15 \%$.

\section{Conflict of Interests}

The authors declare that there is no conflict of interests regarding the publication of this paper.

\section{References}

[1] V. Mechtcherine, V. N. Nerella, and K. Kasten, "Testing pumpability of concrete using Sliding Pipe Rheometer," Construction and Building Materials, vol. 53, pp. 312-323, 2014.

[2] M. Choi, N. Roussel, Y. Kim, and J. Kim, "Lubrication layer properties during concrete pumping," Cement and Concrete Research, vol. 45, no. 1, pp. 69-78, 2013.

[3] H. Xie, F. Liu, Y. Fan et al., "Workability and proportion design of pumping concrete based on rheological parameters," Construction and Building Materials, vol. 44, pp. 267-275, 2013.

[4] D. Kaplan, Pompage des bétons, Etudes et recherches des laboratoires des Ponts et Chaussées, Rapp. LCPC, Paris, France, 2000.

[5] D. Kaplan, F. de Larrard, and T. Sedran, "Design of concrete pumping circuit," ACI Materials Journal, vol. 102, no. 2, pp. 110117, 2005.

[6] H. D. Le, Etude de l'effet de la couche limite sur les profils de vitesse du béton pompé [Ph.D. thesis], University of Cergy Pontoise, Cergy-Pontoise, France, 2014. 
[7] G. H. Tattersall, The Rheology of Fresh Concrete, Pitman Books, London, UK, 1983.

[8] F. de Larrard, T. Sedran, C. Hu, J. C. Sitzkar, M. Joly, and F. Derkx, "Evolution of the workability of super plasticized concrete: assessment with BTRHEOM rheometer," in Proceedings of the International RILEM Conference on Production Methods and Workability of Concrete, pp. 377-388, Paisley, Scotland, 1996.

[9] S. Jacobsen, L. Haugan, T. A. Hammer, and E. Kalogiannidis, "Flow conditions of fresh mortar and concrete in different pipes," Cement and Concrete Research, vol. 39, no. 11, pp. 9971006, 2009.

[10] T. T. Ngo, E. H. Kadri, F. Cussigh, and R. Bennacer, "Measurement and modeling of fresh concrete viscous constant to predict pumping pressures," Canadian Journal of Civil Engineering, vol. 38, no. 8, pp. 944-956, 2011.

[11] J. Morinaga, "Pumpability of concrete and pumping pressure in pipelines, fresh concrete: important properties and their measurement," in Proceedings of RILEM Conference, vol. 7, pp. 1-39, 1973.

[12] J. F. Best and R. O. Lane, "Testing for optimum pumpability of concrete," ACI Concrete International, vol. 2, no. 10, pp. 9-17, 1980.

[13] N. Bleschik, Mechanical Properties and Rheology of Concrete, Minsk, Russia, 1977.

[14] F. Chapdelaine, Étude fondamentale et pratique sur le pompage $d u$ béton [Ph.D. thesis], Faculty of the Higher Studies of Laval University, Québec, Canada, 2007.

[15] T. T. Ngo, E. H. Kadri, R. Bennacer, and F. Cussigh, "Use of tribometer to estimate interface friction and concrete boundary layer composition during the fluid concrete pumping," Construction and Building Materials, vol. 24, no. 7, pp. 1253-1261, 2010.

[16] D. Feya, Interactions between Rheological Properties and Pumping of Self-Compacting Concrete, Ghent University, 2009.

[17] T. T. Ngo, Comment Déterminer les Paramètres de Pompage des Bétons Fluides? Editions Universitaires Europeennes, Paris, France, 2010.

[18] T. T. Ngo, Influence de la composition des bétons sur les paramètres de pompage et validation d'un modèle de prévision de la constante visqueuse [Ph.D. thesis], University of Cergy Pontoise, Cergy-Pontoise, France, 2009.

[19] D. Feys, R. Verhoeven, and G. de Schutter, "Evaluation of time independent rheological models applicable to fresh selfcompacting concrete," Applied Rheology, vol. 17, no. 5, pp. 1-10, 2007.

[20] T.-T. Ngo, E.-H. Kadri, F. Cussigh, and R. Bennacer, "Relationships between concrete composition and boundary layer composition to optimise concrete pumpability," European Journal of Environmental and Civil Engineering, vol. 16, no. 2, pp. 157-177, 2012.

[21] F. de Larrard and A. Belloc, "L'influence du granulat sur la résistance à la compression des bétons," Bulletin des Laboratoires des Ponts et Chaussées, vol. 219, pp. 41-52, 1999.

[22] F. De Larrard and T. Sedran, "Mixture-proportioning of highperformance concrete," Cement and Concrete Research, vol. 32, no. 11, pp. 1699-1704, 2002.

[23] J. Gołaszewski and J. Szwabowski, "Influence of superplasticizers on rheological behaviour of fresh cement mortars," Cement and Concrete Research, vol. 34, no. 2, pp. 235-248, 2004.

[24] J. E. Wallevik, "Relationship between the Bingham parameters and slump," Cement and Concrete Research, vol. 36, no. 7, pp. 1214-1221, 2006.
[25] T.-T. Ngo, E.-H. Kadri, F. Cussigh, R. Bennacer, and R. Duval, "Practical tribometer to estimate pumpability of fresh concrete," Journal of Asian Architecture and Building Engineering, vol. 9, no. 1, pp. 229-236, 2010.

[26] J. Murata and H. Kikukawa, "Viscosity equation for fresh concrete," ACI Materials Journal, vol. 89, no. 3, pp. 230-237, 1992.

[27] C. Hu, F. De Larrard, T. Sedran, C. Boulay, F. Bosc, and F. Deflorenne, "Validation of BTRHEOM, the new rheometer for soft-to-fluid concrete," Matériaux et Constructions, vol. 29, no. 194, pp. 620-631, 1996.

[28] C. F. Ferraris and F. de Larrard, "Testing and modelling of fresh concrete rheology," Tech. Rep. NISTIR 6094, National Institute of Standards and Technology, Gaithersburg, Md, USA, 1998. 

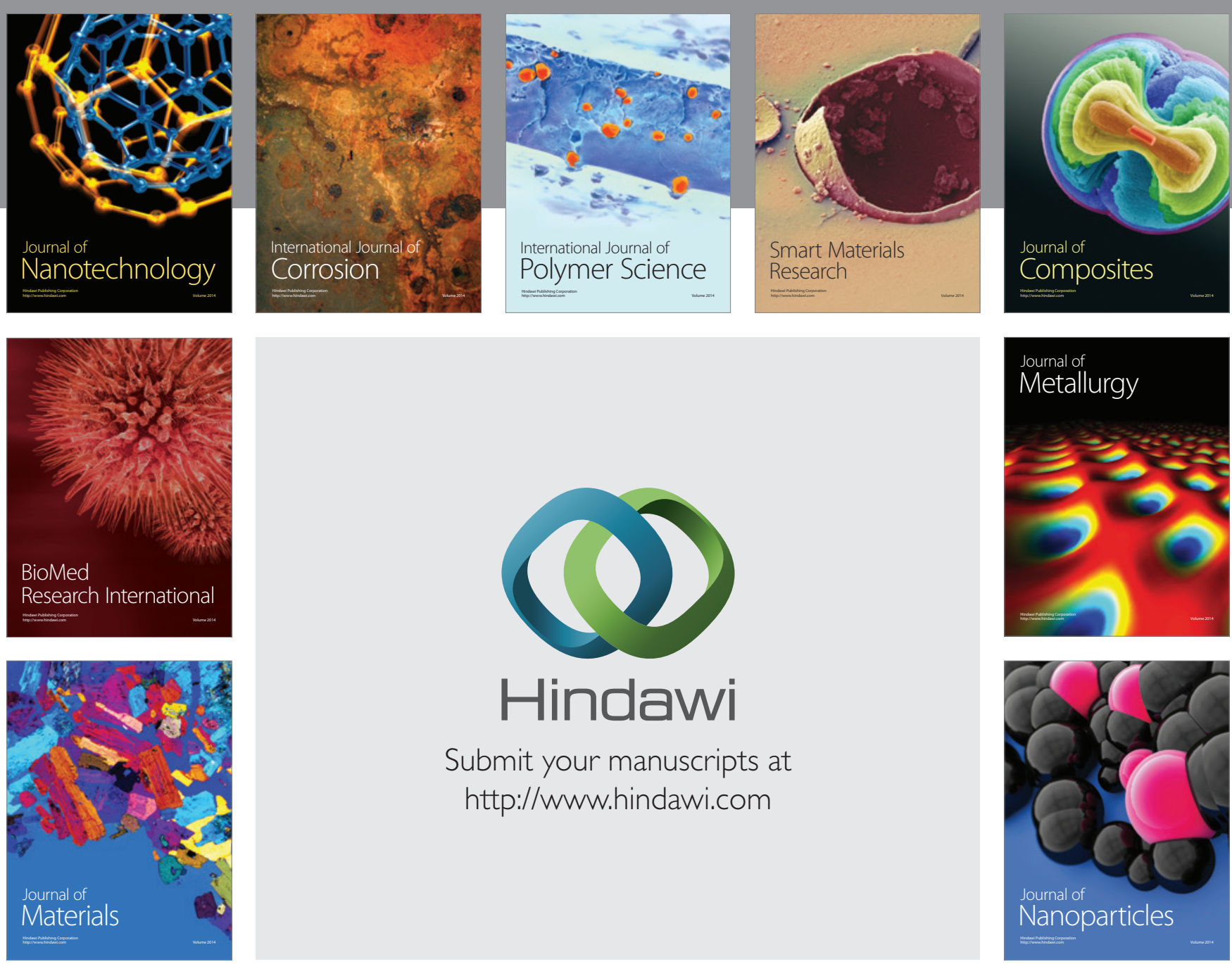

Submit your manuscripts at http://www.hindawi.com
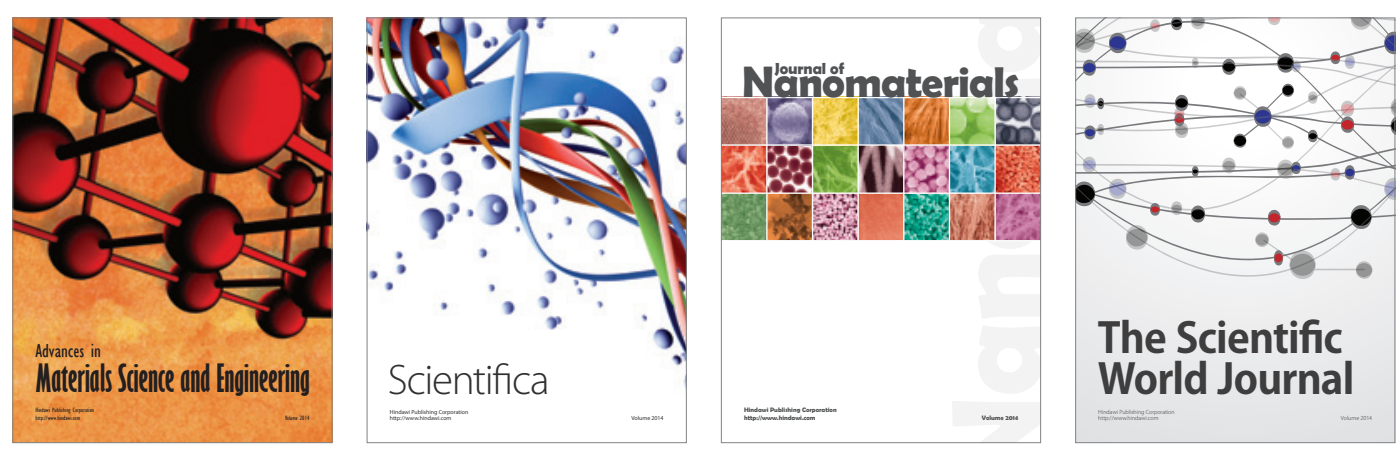

\section{The Scientific World Journal}
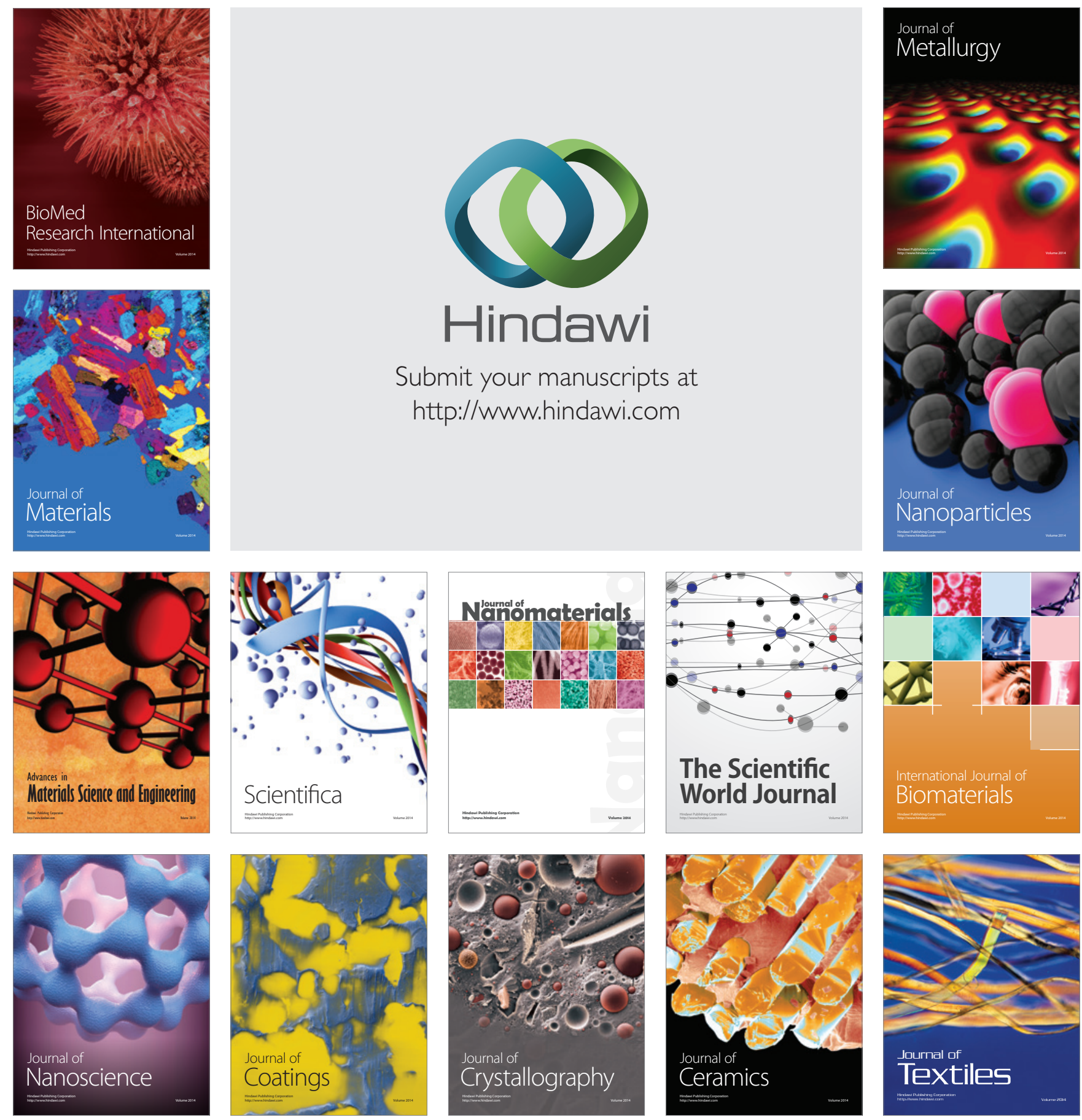